\title{
Similia similibus curentur: o princípio de cura homeopático fundamentado na farmacologia moderna
}

\author{
Similia similibus curentur: the homeopathic healing principle \\ based on modern pharmacology
}

\author{
Marcus Zulian Teixeira
}

DOI: http://dx.doi.org/10.11606/issn.1679-9836.v92i3p183-203

Teixeira MZ. Similia similibus curentur: o princípio de cura homeopático fundamentado na farmacologia moderna /Similia similibus curentur: the homeopathic healing principle based on modern pharmacology. Rev Med (São Paulo). 2013 jul.-set.,92(3):183-203.

RESUMO: O modelo homeopático de tratamento das doenças utiliza o 'princípio da semelhança' como método terapêutico, empregando medicamentos que causam determinados sintomas em indivíduos sadios para tratar sintomas semelhantes em indivíduos doentes (similia similibus curentur), com o intuito de estimular uma reação curativa do organismo contra os seus próprios distúrbios. Esta reação secundária (vital, homeostática ou paradoxal) do organismo está fundamentada no estudo do 'efeito rebote' dos fármacos modernos, evento adverso que pode causar transtornos graves após a descontinuação de diversas classes de tratamentos convencionais que utilizam o 'princípio dos contrários' como prática terapêtica (contraria contrariis curentur). Embora o fenômeno rebote seja um evento adverso estudado pela farmacologia moderna, ele é desconhecido pelos profissionais da saúde, privando a classe médica de um conhecimento necessário e fundamental ao manejo seguro dos fármacos. Apesar de se expressar numa pequena proporção de indivíduos suscetíveis, o efeito rebote assume importância epidemiológica em vista do enorme consumo de medicamentos pela população e da falta de esclarecimentos sobre o fenômeno. Este artigo apresenta uma revisão atualizada sobre o efeito rebote das drogas, relacionando-o ao princípio de cura homeopático.

DESCRITORES: Homeopatia; Lei dos semelhantes; Ação farmacodinâmica do medicamento homeopático; Efeito secundário; Efeito rebote.

\begin{abstract}
The homeopathic model of treatment of diseases uses the 'principle of similarity' as therapeutic method, employing drugs that cause certain symptoms in healthy individuals to treat similar symptoms in sick individuals (similia similibus curentur), seeking to stimulate a healing reaction of the organism against its own disorders. This secondary (vital, homeostatic or paradoxical) reaction of the organism is based on the study of the 'rebound effect' of modern drugs, iatrogenic event that can cause serious disorders after the discontinuation of several classes of conventional treatments that use the 'principle of contraries' as therapeutic practice (contraria contrariis curentur). Although the rebound phenomenon is an adverse event studied by modern pharmacology, it is unknown by health professionals, depriving the medical class of a necessary and fundamental knowledge to the safe management of drugs. Despite expressing itself in a small proportion of susceptible individuals, the rebound effect assumes epidemiological importance in view of the enormous consumption of drugs by the population and the lack of clarity on the phenomenon. This article presents an updated review on the rebound effect of drugs, relating it to the homeopathic healing principle.
\end{abstract}

KEY WORDS: Homeopathy; Law of similars; Pharmacodynamic action of homeopathic remedy; Secondary effect; Rebound effect.

NOTA: Versão atualizada em dezembro de 2013, conforme ERRATA publicada na Rev Med (São Paulo). 2013 out.-dez:;92(4):281.

MD, PhD. Coordenador da disciplina optativa "Fundamentos da Homeopatia" (MCM0773) da Faculdade de Medicina da Universidade de São Paulo (FMUSP).

Endereço para correspondência: Marcus Zulian Teixeira. Hospital das Clínicas da FMUSP. Serviço de Clínica Médica Geral. Av. Dr. Enéas de Carvalho Aguiar, 155, $4^{\circ}$ andar - bloco 6. CEP: 05403-900. São Paulo, SP. E-mail: mzulian@usp.br 


\section{INTRODUÇÃO}

$\mathbf{O}$ método homeopático de tratamento das doenças baseia-se em quatro pilares ou pressupostos fundamentais: 'princípio de cura pela similitude', 'experimentação de medicamentos em indivíduos sadios', uso de 'medicamentos dinamizados' e prescrição de 'medicamentos individualizados'. Embora se atribua grande importância ao 'medicamento dinamizado' (diluições e agitações seriadas dos medicamentos, 'doses infinitesimais' ou 'ultradiluições'), incorporado posteriormente ao modelo homeopático para minimizar as possíveis agravações sintomáticas advindas da aplicação da similitude terapêutica, as duas primeiras premissas são a base da episteme homeopática, restando ao medicamento individualizado (escolhido segundo a "totalidade característica de sintomas") a condição inerente para que a reação terapêutica do organismo seja despertada $^{1,2}$.

Após observar que medicamentos utilizados para curar sintomas em indivíduos doentes causavam sintomas semelhantes quando experimentados por indivíduos sadios, Samuel Hahnemann buscou confirmar esta observação fenomenológica através do método científico da 'analogia' e da 'enumeração', encontrando centenas de confirmações ('argumentos fortes') nos relatos clínicos de médicos de todas as épocas e em diversas classes de drogas. Utilizandose da lógica aristotélica indutiva (modus ponens), enunciou o princípio de cura pela similitude: para uma substância medicinal curar sintomas no individuo doente ela deve causar sintomas semelhantes no indivíduo sadio.

Inaugurando a homeopatia em 1796 com a publicação do Ensaio sobre um novo princípio para se averiguar o poder curativo das drogas ${ }^{3}$, Hahnemann descreveu nesta revisão as 'ações primárias diretas das drogas' e as consequentes e opostas 'ações secundárias indiretas do organismo', organizando os efeitos farmacológicos de dezenas de medicamentos de sua época. Exemplificando esta sistematização no estudo da planta Digitalis purpurea ou 'dedaleira' (fonte das drogas 'digitálicas' modernas), empregada desde aquela época como medicamento antiarrítmico segundo a similitude terapêutica:

> Ação primária direta (patogenética) da droga: deprime a circulação, diminui a frequência dos batimentos cardíacos pela metade produzindo pulso lento e macio; produz inflamação nos gânglios, com sensação pruriginosa e dolorosa; inflamação das glândulas meibomianas; visões obscurecidas, parecendo que os objetos têm várias cores; convulsões; dores de cabeça violentas, vertigem, dor no estômago, grande diminuição dos poderes vitais, sensação de dissolução e aproximação da morte;

> Ação secundária indireta (curativa) do organismo: melhora da circulação com aumento da frequência cardíaca e pulso rápido, duro e pequeno; eficiente em inchaços ganglionares; cura das inflamações meibomianas; remove afecções semelhantes na retina; proveitosa em algumas formas de epilepsia, desde que acompanhadas de outros sintomas mórbidos que produz; cura de sintomas associados à sensação de dissolução e aproximação da morte.

Nos parágrafos 63 a 65 do Organon da arte de curar $^{4}$, obra magna do modelo homeopático, Hahnemann esboçou uma explicação fisiológica para esta 'lei natural de cura', fundamentando o princípio da similitude na ação primária da droga e na subsequente e oposta ação secundária ou reação vital do organismo:

"Toda força que atua sobre a vida, todo medicamento afeta, em maior ou menor escala, a força vital, causando certa alteração no estado de saúde do Homem por um período de tempo maior ou menor. A isso se chama ação primária. [...] A essa ação, nossa força vital se esforça para opor sua própria energia. Tal ação oposta faz parte de nossa força de conservação, constituindo uma atividade automática da mesma, chamada ação secundária ou reação" (Organon, parágrafo 63).

Hahnemann exemplificou este 'mecanismo universal' de ação dos medicamentos (ação primária da droga seguida pela ação secundária e oposta do organismo) observado nas distintas sensações e funções orgânicas, nos efeitos fisiológicos dos tratamentos paliativos (antagônicos, antipáticos, enantiopáticos ou de 'ação contrária' aos sintomas manifestos) empregados em sua época:

“[...] A mão que é banhada em água quente, a princípio fica muito mais quente do que a outra não banhada (ação primária); porém, após ser retirada da água quente e estar completamente enxuta novamente, torna-se fria depois de algum tempo e, finalmente, muito mais fria do que a outra (ação secundária). Depois de aquecida por um intenso exercício físico (ação primária), a pessoa é atingida por frio e tremores (ação secundária). Para quem ontem se aqueceu com bastante vinho (ação primária), hoje qualquer ventinho é muito frio (ação oposta do organismo, secundária). Um braço mergulhado por tempo muito longo em água muito fria é, a princípio, muito mais pálido e frio (ação primária) do que o outro; porém, fora da água e enxuto, torna-se, a seguir, não apenas mais quente do que o outro, mas também vermelho, quente e inflamado (ação secundária, reação da força vital). À ingestão de café forte, segue-se uma superexcitação (ação primária); porém, um grande relaxamento e sonolência (reação, ação secundária) permanecem por algum tempo se não continuarem a ser suprimidos através de mais café (paliativo, de curta duração). Após o sono profundo e entorpecedor produzido pelo ópio (ação primária), a noite seguinte será tanto mais insone (reação, ação secundária). Depois da constipação produzida pelo ópio (ação primária), segue-se a diarréia (ação secundária) e, após purgativos que irritam os intestinos, sobrevêm obstrução e constipação por vários dias (ação secundária). Assim, por toda parte, após a ação primária de uma potência capaz de, em grandes doses, transformar profundamente o 
Teixeira MZ. Similia similibus curentur: o princípio de cura homeopático fundamentado na farmacologia moderna.

estado de saúde do organismo sadio, é justamente o oposto que sempre ocorre (se, como se disse, tal fato realmente existe) na ação secundária, através de nossa força vital" (Organon, parágrafo 65).

O tratamento homeopático emprega esta ação secundária (reação vital) do organismo como resposta terapêutica, administrando aos indivíduos doentes as drogas que causam sintomas semelhantes nos indivíduos sadios (similia similibus curentur), com o intuito de despertar uma reação vital curativa do organismo contra seus próprios distúrbios, restabelecendo o "estado normal de saúde".

Enfatizando que esta ação secundária do organismo (de caráter oposto à ação primária da droga) pode ser observada "em todos os casos, sem exceção", com doses ponderais ou infinitesimais, em indivíduos sadios ou doentes, Hahnemann elevou o princípio da similitude à categoria de 'lei natural' (Organon, parágrafos 58, 61, 110-112):

"Nas descrições mais antigas dos efeitos muitas vezes perigosos dos medicamentos ingeridos em doses excessivas, notam-se também certos estados que surgem não no início, mas no fim desses tristes acontecimentos, que eram de natureza exatamente oposta aos que haviam surgido inicialmente. Esses sintomas opostos da ação primária (§63) ou ação própria dos medicamentos sobre a força vital são a reação do princípio vital do organismo, portanto, ação secundária (§ 62-67), da qual, contudo, raramente ou quase nunca resta o menor vestígio em experiências feitas com doses moderadas em organismos sadios; quando, porém, as doses são pequenas, nunca resta absolutamente nada. No processo homeopático de cura, o organismo vivo produz, contra tais doses, tão somente a reação necessária para restabelecer o estado normal de saúde" (Organon, parágrafo 112).

Descrevendo os resultados desagradáveis do emprego indiscriminado de medicamentos com ação antagônica aos sintomas manifestos (Organon, parágrafos 59-61), Hahnemann alertou para os riscos desta ação secundária (reação vital) do organismo produzir efeitos indesejáveis, "um outro mal maior ou, muitas vezes, a incurabilidade, o perigo para a vida e a morte". Dessa forma, negando a eficácia dos tratamentos paliativos ou antipáticos (princípio dos contrários) no tratamento das doenças crônicas, Hahnemann validou o tratamento homeopático (princípio da similitude terapêutica) segundo a lógica aristotélica dedutiva modus tollens ou 'modo que afirma pela negação' ('prova indireta' ou 'hipótese nula' da bioestatística moderna):

“Se, como é muito natural prever, resultados desagradáveis sobrevêm de tal emprego antipático dos medicamentos, o médico comum imagina, então, que a cada piora da doença é suficiente uma dose mais forte do medicamento, com o que, do mesmo modo, há um alívio apenas passageiro e, quando quantidades cada vez maiores do paliativo se fazem necessárias, segue-se outro mal maior ou, muitas vezes, a incurabilidade, o perigo para a vida e a morte; nunca, porém, a cura de um mal há algum tempo ou há muito tempo existente" (Organon, parágrafo 60).

Segundo a racionalidade científica e os conceitos farmacológicos modernos, a ação primária descrita por Hahnemann corresponde aos efeitos terapêuticos, adversos e colaterais das drogas convencionais. Por outro lado, a ação secundária ou reação vital do modelo homeopático corresponde ao efeito rebote ou reação paradoxal do organismo, observada após a descontinuação de inúmeras classes de fármacos que atuam de forma contrária aos sintomas das doenças (drogas paliativas, antagônicas ou enantiopáticas).

Com o intuito de embasar o princípio de cura homeopático (ação secundária ou reação vital do organismo) perante a farmacologia clínica e experimental, desde 1996 vimos estudando de forma sistemática o 'efeito rebote' dos fármacos modernos ${ }^{5-16}$. Esta revisão atualizada sobre o fenômeno rebote tem como objetivo fundamentar cientificamente o modelo homeopático de tratamento das doenças, além de alertar a classe médica sobre esse evento adverso que pode trazer sérios riscos à saúde dos pacientes.

\section{SIMILITUDE NA FARMACOLOGIA MODERNA}

Por definição ${ }^{17}$, 'efeito rebote' significa a "produção de sintomas opostos aumentados quando terminou o efeito de uma droga ou o paciente já não responde à droga; se uma droga produz um efeito rebote, a condição em que ela foi usada para tratar pode retornar ainda mais forte quando a droga é descontinuada ou perde a eficácia". Analogamente, 'efeito (reação) paradoxal' significa uma resposta da droga oposta ao efeito previsto.

De forma generalizada, podemos entender o efeito rebote como uma manifestação automática e instintiva dos mecanismos homeostáticos do organismo no sentido de restabelecer o estado inicial alterado pela ação primária da droga, promovendo um efeito oposto e contrário ao esperado. Descrito em 1860 pelo fisiologista da Sorbonne Claude Bernard como 'fixité du milieu intérieur', o termo 'homeostase' foi introduzido em 1929 pelo fisiologista de Harvard Walter Bradford Cannon para nomear a tendência ou a capacidade dos seres vivos em manter a constância do meio interno através de auto-ajustes em seus processos fisiológicos. Estes ajustes fisiológicos compensatórios estão presentes em todos os níveis da organização biológica, desde os simples mecanismos celulares até as complexas funções psicoemocionais.

Segundo diversas revisões que estudaram o fenômeno ${ }^{18-21}$, o efeito rebote ocorre após a suspensão das drogas com ação contrária às manifestações sintomáticas ou fisiológicas das doenças (princípio dos contrários). Também denominada como 'síndrome da retirada' (withdrawal syndrome), esta interrupção do efeito direto ou primário do fármaco permite a expressão da reação homeostática 
do organismo no sentido de retornar ao estado basal, produzindo sintomas paradoxais (rebote) de intensidade e/ou frequência superior aos inicialmente suprimidos. Explicado, parcialmente, pela alteração na regulação ou na capacidade de resposta dos receptores fisiológicos envolvidos, o efeito rebote necessita de um tempo mínimo e específico ('time-point') para se manifestar, período este relacionado à metabolização da droga ('meia-vida') ou à ausência do efeito biológico, podendo também ocorrer em descontinuações temporárias ('posologia inadequada') ou sem que o fármaco seja suspenso ('tolerância medicamentosa').

Com manifestações e características distintas do 'reaparecimento da doença de base após a ausência do efeito farmacológico do medicamento', o fenômeno rebote apresenta sintomas de magnitudes superiores aos inicialmente suprimidos pelo tratamento paliativo ( período variável de horas a meses. Por suas características idiossincrásicas, se manifesta numa pequena proporção de indivíduos suscetíveis, sendo mais significativo em algumas classes de drogas.

Inicialmente descritas por Hahnemann (Organon, parágrafos $59,64,69)^{4}$, as propriedades dessa ação secundária (reação vital) do organismo estão confirmadas nos estudos do efeito rebote (reação paradoxal) da farmacologia clínica e experimental ${ }^{3-12}$ : (i) se manifesta apenas em indivíduos suscetíveis; (ii) não depende do tipo de droga, do tempo de uso ou do tipo de sintoma (doença); (iii) ocorre após o término da ação primária (efeito biológico) da droga, como uma manifestação automática e instintiva do organismo; (iv) provoca sintomas opostos aos da ação primária da droga e de magnitude superior aos sintomas anteriores ao tratamento; (v) a magnitude de seu efeito é proporcional à intensidade da ação primária da droga.

Com o intuito de investigar a manifestação do efeito rebote ('rebound effect') ou reação paradoxal ('paradoxical reaction') do organismo nos fármacos modernos, pesquisamos compêndios farmacológicos ${ }^{22,23}$ e trabalhos científicos publicados nas principais bases de dados, encontrando descrições de piora ou agravamento dos sintomas basais após a descontinuação de inúmeras classes de drogas com ação paliativa ou antagônica aos sintomas, que corresponde à ação secundária ou reação vital do modelo homeopático.

Ilustrando esta universalidade do fenômeno rebote perante as inúmeras classes de fármacos enantiopáticos modernos $^{5-16}$, drogas utilizadas no tratamento da angina pectoris (beta-bloqueadores, bloqueadores dos canais de cálcio, nitratos, dentre outros), promovendo a melhora da angina pela sua ação primária, podem desencadear exacerbações na intensidade e/ou na frequência da dor torácica após sua descontinuação, em decorrência do efeito rebote. Drogas utilizadas no controle da hipertensão arterial (agonistas alfa-2 adrenérgicos, beta-bloqueadores, inibidores da ECA, inibidores da MAO, nitratos, nitroprussiato de sódio, hidralazina, dentre outros) podem despertar hipertensão arterial rebote após cessar o efeito primário anti-hipertensivo. Medicamentos antiarrítmicos (adenosina, amiodarona, beta-bloqueadores, bloqueadores dos canais de cálcio, disopiramida, flecainida, lidocaína, mexiletina, moricizina, procainamida, dentre outros), após a interrupção do tratamento, podem provocar uma exacerbação rebote das arritmias ventriculares basais. Drogas com efeito antitrombótico (argatroban, bezafibrato, heparina, salicilatos, varfarina, clopidogrel, dentre outros), empregadas por sua ação primária na profilaxia da trombose sanguínea, podem promover complicações trombóticas rebote. Drogas que apresentam efeito primário vasculoprotetor (pleiotrópico) (estatinas, por exemplo) podem despertar acidentes vasculares paradoxais.

De forma análoga, no emprego de fármacos psiquiátricos como os ansiolíticos (barbitúricos, benzodiazepinas, carbamatos, dentre outros), sedativohipnóticos (barbitúricos, benzodiazepinas, morfina, prometazina, zopiclone, dentre outros), estimulantes do sistema nervoso central (anfetaminas, cafeína, cocaína, mazindol, metilfenidato, dentre outros), antidepressivos (tricíclicos, inibidores da MAO, inibidores da recaptação de serotonina, dentre outros) ou antipsicóticos (clozapina, fenotiazínicos, haloperidol, pimozida, dentre outros) podese observar uma reação paradoxal do organismo após cessar a atividade biológica dos mesmos, promovendo sintomas opostos aos esperados na sua utilização terapêutica primária, com piora do quadro original. Drogas com ação antiinflamatória (corticosteróides, ibuprofeno, indometacina, paracetamol, salicilatos, dentre outros) podem desencadear inflamação rebote após o término de sua ação primária, assim como eventos tromboembólicos paradoxais (ibuprofeno, indometacina, diclofenaco, salicilatos, rofecoxibe, celecoxibe, dentre outros) após sua ação antiagregante plaquetária primária. Fármacos com ação primária analgésica (cafeína, bloqueadores dos canais de cálcio, clonidina, ergotamina, metisergida, opióides, salicilatos, dentre outros) podem apresentar importante hiperalgesia rebote.

Diuréticos (furosemida, torasemida, trianterene, dentre outros), utilizados para diminuir a volemia em diversos estados mórbidos (edema, hipertensão arterial, ICC, dentre outros), podem causar retenção rebote de sódio e potássio, aumentando a volemia basal. Broncodilatores (adrenérgicos, cromoglicato dissódico, epinefrina, ipatropio, nedocromil, salmeterol, formoterol, dentre outros), empregados no tratamento da asma brônquica, podem promover broncoconstrição rebote como resposta secundária do organismo à descontinuação do tratamento. Medicamentos utilizados no tratamento das gastrites e das úlceras gastroduodenais por sua ação primária antidispéptica (antiácidos, antagonistas do receptor $\mathrm{H}_{2}$, 
misoprostol, sucralfato, inibidores das bombas de próton, dentre outros) podem despertar aumento rebote na produção de ácido clorídrico e gastrina, com agravamento do quadro de base. Drogas indicadas para o tratamento da osteoporose (bifosfonatos, denosumabe, odanacatibe, dentre outros) podem causar fraturas atípicas paradoxais após o término de seu efeito biológico (meia-vida), em consequência do aumento rebote da atividade osteoclástica. Drogas imunomoduladoras (natalizumabe, fingolimode, dentre outros), utilizadas no tratamento da esclerose múltipla, podem causar agravamento paradoxal da doença após o término de sua atividade biológica. Dentre outras ${ }^{5-16}$.

Apesar de se manifestar numa minoria de indivíduos (caráter idiossincrático), a magnitude do efeito rebote pode desencadear eventos adversos de grandes repercussões fisiológicas em algumas classes de fármacos modernos, reiterando a validade e a importância do seu uso terapêutico segundo o princípio da similitude (princípio de cura homeopático).

\section{EFEITOREBOTEDASDROGASANTIAGREGANTES PLAQUETÁRIAS ${ }^{7,8,13,16}$}

\section{Ácido acetilsalicílico (AAS)}

O AAS pertence à classe das drogas antiinflamatórias não esteroidais (AINEs) e não seletivas das enzimas ciclooxigenases (COXs), que catalisam a conversão do ácido araquidônico em prostaglandinas (COX-2) e tromboxanos (COX-1). Largamente utilizado na prevenção de eventos tromboembólicos, apresenta a propriedade primária de evitar a formação de trombos ao inibir a COX-1 [mediadora da atividade plaquetária ao estimular a síntese do tromboxano A2 $\left(\mathrm{TXA}_{2}\right)$ ] e a agregação plaquetária. Estudos clínicos e experimentais evidenciaram o tromboembolismo rebote após a descontinuação do AAS e outras drogas antiagregantes plaquetárias, desencadeando ataques isquêmicos transitórios (AIT), infarto agudo do miocárdio (IAM) e acidente vascular cerebral (AVC).

Após a descontinuação de drogas antiagregantes plaquetárias empregadas na profilaxia do tromboembolismo, estudos experimentais ${ }^{24,25}$ evidenciaram a ocorrência de uma reação rebote ou paradoxal do organismo estimulando a produção de COX-1 e a atividade plaquetária (TXA2) a níveis superiores aos anteriores ao tratamento, aumentando assim a probabilidade de eventos tromboembólicos em indivíduos suscetíveis.

Em comparação à manutenção do tratamento, estudos observacionais evidenciaram riscos 3-4 vezes maiores de acidentes vasculares (AIT, IAM e AVC) após a suspensão do $\mathrm{AAS}^{26-28}$, relacionando 4\% desses eventos à descontinuação recente (6-30 dias) das drogas antiagregantes plaquetárias ${ }^{29,30}$. Meta-análise ${ }^{31} \mathrm{com}$ 50.279 pacientes em risco de desenvolver doença arterial coronariana (DAC) comparou a 'adesão à terapia' na prevenção de DAC e na revascularização do miocárdio com a 'suspensão do AAS' na incidência de DAC aguda e na implantação de 'stent' farmacológico, evidenciando que a não adesão ou suspensão do AAS esteve associada a um risco três vezes maior de ocorrência de eventos cardíacos graves (odds ratio, OR 3,14; IC 95\% 1,75-5,61). Outra meta-análise (49.590 pacientes) ${ }^{32}$ mostrou que $10 \%$ das síndromes vasculares agudas são precedidas pela suspensão do AAS em intervalos de 4-8 dias para eventos coronarianos, 11-14 dias para eventos cerebrais e 18-26 dias para eventos periféricos.

Alterando o paradigma vigente, estudos recentes alertam sobre os riscos tromboembólicos (AIT, IAM e AVC) associados à suspensão do AAS no período perioperatório, priorizando a manutenção do AAS intraoperatório, apesar do conhecido risco hemorrágico ${ }^{33,34}$.

Confirmando a agregação plaquetária rebote como um 'fenômeno natural e universal', todas as classes de antiagregantes plaquetários (salicilatos, heparina, varfarina, clopidogrel, dentre outros) induzem o tromboembolismo rebote após a sua suspensão, podendo causar acidentes vasculares graves e fatais ${ }^{35-39}$.

\section{Antiinflamatórios não esteroidais (AINEs)}

Diversos mecanismos estão relacionados ao aumento do risco vascular pelo uso dos AINEs: produção reduzida de prostaciclina no endotélio vascular, supressão da síntese do óxido nítrico, diminuição da neovascularização, supressão da atividade da adrenomedulina, produção aumentada de radicais livres, dentre outros. Esses mecanismos também afetam a atividade plaquetária, que desempenha um papel crucial no desenvolvimento dos eventos vasculares tromboembólicos. De forma análoga ao AAS, eventos vasculares rebote são descritos após a suspensão de todas as classes de AINEs (inibidores seletivos e não seletivos das COXs).

Confirmando resultados experimentais ${ }^{40-43}$ que evidenciaram agregação plaquetária rebote após a descontinuação dos AINEs, estudos observacionais mostraram aumento no risco de $\mathrm{IAM}^{44}$ e $\mathrm{AVC}^{45}$ nos indivíduos que suspenderam a droga 1 mês antes da manifestação do evento. Em relação aos antiinflamatórios inibidores seletivos da COX-2 (rofecoxibe, celecoxibe), estudos observacionais ${ }^{46-50}$ também evidenciaram alto risco de IAM, com eventos ocorrendo numa média de 9 (6-13) dias após a suspensão de baixas doses do fármaco. A duração do tratamento não esteve associada ao aumento do risco, que se manteve elevado nos primeiros 7 dias após a suspensão da droga e retornou à linha de base entre os dias 8 e 30, caracterizando o fenômeno rebote.

Analisando de forma comparativa o risco relativo (RR) de hospitalização por IAM em todas as classes de AINEs, estudo de caso-controle ${ }^{51}$ evidenciou resultados 
semelhantes: rofecoxibe (RR 1,36; IC 95\% 1,18-1,58), diclofenaco (RR 1,40; IC 95\% 1,19-1,65), meloxicam (RR 1,24; IC 95\% 1,06-1,45) e indometacina (RR 1,36; IC $95 \% 1,15-1,61)$. De forma análoga, revisão sistemática ${ }^{52}$ com 1,60 milhão de pacientes mostrou a relação entre eventos cardiovasculares e o tratamento inicial ( $<30$ dias) com AINEs, em comparação à ausência de tratamento: rofecoxibe (RR 1,33; IC 95\% 1,00-1,79; para doses $\leq$ $25 \mathrm{mg} / \mathrm{dia})$ e (RR 2,19; IC 95\% 1,64-2,91; para doses > $25 \mathrm{mg} / \mathrm{dia}$ ); diclofenaco (RR 1,40; IC 95\% 1,16-1,70), meloxicam (RR 1,25; IC 95\% 1,00-1,55) e indometacina (RR 1,30; IC 95\% 1,07-1,60). Outra metanálise ${ }^{53}(145.373$ pacientes) evidenciou resultados semelhantes: rofecoxibe (RR 1,42; IC 95\% 1,13-1,78) e diclofenaco (RR 1,63; IC 95\% 1,12-2,37).

De forma análoga ao AAS e demais antiagregantes plaquetários, os AINEs induzem o tromboembolismo rebote após a sua suspensão, com evidências científicas crescentes $^{54-57}$ da possibilidade de causarem eventos vasculares fatais, fundamentando a ação secundária e oposta do organismo após uma ação primária paliativa (princípio da similitude).

\section{EFEITO REBOTE DAS DROGAS BRONCODI- LATADORAS $^{7,9,13,16}$}

Nasúltimas décadas, diversos estudos ${ }^{58-65}$ confirmaram a ocorrência de 'broncoconstrição rebote' após interrupção parcial ou completa de drogas broncodilatadoras, com 'agravamento da asma'e 'aumento da reatividade brônquica'. $\mathrm{Na}$ explicação fisiológica desse fenômeno, o uso regular de drogas beta-agonistas está relacionado à tolerância aos efeitos da droga e à piora no controle da doenç ${ }^{66-70}$. A 'tolerância' resulta de um mecanismo de retroalimentação negativa do sistema beta-adrenérgico, como uma resposta adaptativa à estimulação dos receptores, causando desacoplamento e internalização (dessensibilização) dos receptores, seguidos por uma diminuição na densidade e na expressão do gene dos receptores ('down regulation') ${ }^{71}$. Apesar da manutenção de certo grau de broncodilatação, o uso regular de beta-agonistas causa hiperreactividade brônquica. Esses efeitos, juntamente com uma redução na resposta ao subsequente resgate beta-agonista (tolerância), podem piorar o controle da asma, em vista da ausência do aumento evidente dos sintomas ${ }^{70,72}$. Como descrito em estudos anteriores $^{58-65}$, 'hiperreactividade brônquica' é o mesmo que 'hiperreactividade rebote' ou 'broncoconstrição rebote ${ }^{73}$

Mega ensaio clínico randomizado, duplo-cego e placebo controlado (SMART, 26.355 indivíduos), interrompido precocemente em 2002 após análise preliminar indicar risco de morte por asma nos pacientes que usavam salmeterol (beta-2 agonista de longa duração ou LABA $)^{74,75}$, teve seus resultados definitivos publicados somente em $2006^{76}$, evidenciando mortes relacionadas a eventos respiratórios (RR 2,16; IC 95\% 1,06-4,41), mortes relacionadas à asma (RR 4,37; IC 95\% 1,25-15,34) e mortes relacionadas à asma com experiências de risco de morte (RR 1,71; IC 95\% 1,01-2,89).

Meta-análise ${ }^{77}$ envolvendo 33.826 pacientes asmáticos em uso de LABAs (salmeterol, formoterol) evidenciou asma com risco de morte (OR 2,1; IC 95\% 1,53,0 ), asma grave exigindo hospitalização (OR 2,6; IC 95\% $1,6-4,3$ ), ataques de asma fatal (OR 1,8; IC 95\% 1,1-2,9) e mortes relacionadas à asma (OR 3,5; IC 95\% 1,3-9,3). Mesmo com a associação de corticosteróides inalatórios, o risco de hospitalização se manteve alto (OR 2,1; IC 95\% 1,3-3,4), evidenciando a importância e a magnitude do efeito rebote.

Estudo de coorte retrospectivo recente analisou o risco de exacerbações de asma grave em 940.449 pacientes asmáticos, evidenciando internações e entubações significativas associadas ao uso de LABAs, quando comparados aos beta-agonistas de curta duração ${ }^{78}$. Contrariando meta-análise anterior ${ }^{79}$, que mostrou diminuição no risco de mortalidade na asma com a associação do salmeterol ao corticosteróide inalatório, meta-análise recente ${ }^{80}$ evidenciou aumento no risco de morte tanto na monoterapia quanto na associação.

Além de exigir uma estratégia de avaliação e mitigação de risco para o uso seguro desses fármacos ${ }^{81-83}$, a confirmação da broncoconstrição rebote fundamenta a manifestação da reação vital do organismo como mecanismo homeostático.

\section{EFEITO REBOTE DAS DROGAS ANTIDE- PRESSIVAS $^{7,10,13,16}$}

Assim como outras classes de medicamentos enantiopáticos, os antidepressivos apresentam efeito rebote dos sintomas da depressão após a descontinuação do tratamento (ou diminuição das doses recomendadas em indivíduos mais suscetíveis), com alterações evidentes nos receptores e/ou mediadores envolvidos.

Revisões que abordaram o tema ${ }^{19,84}$ descrevem a 'síndrome da retirada' após a suspensão de antidepressivos de todas as classes: "O fenômeno tem sido postulado estar associado com sintomas rebote, com o retorno da depressão após a interrupção abrupta. Sintomas da retirada estão associados com a maioria das classes de antidepressivos se a medicação é interrompida sem uma apropriada diminuição da dose e/ou frequência. Acreditase que o fenômeno associado à retirada de quase todos os antidepressivos, incluindo os inibidores seletivos da recaptação de serotonina (ISRSs), não está relacionado com a dependência à droga, mas com a redução dos níveis de serotonina (5-HT) intrassináptica, em consequência da diminuição do número ou da sensibilidade ('downregulation') dos receptores pós-sinápticos" ${ }^{\prime 84}$. O tratamento consiste em reintroduzir os antidepressivos e a prevenção 
Teixeira MZ. Similia similibus curentur: o princípio de cura homeopático fundamentado na farmacologia moderna.

em retirá-los gradualmente.

Esta síndrome da retirada caracteriza-se pelo 'tempo específico para a emergência do novo' ('time-locked emergence of new') ou 'time-point' e é claramente definida por sinais e sintomas quantificáveis que se manifestam após a suspensão ou diminuição de um antidepressivo utilizado durante algumas semanas ${ }^{85}$. Tipicamente, os pacientes descrevem sintomas temporários que começam no período de uma semana após a interrupção do tratamento, apresentam intensidade leve e seguem um curso de tempo limitado, com a duração de até três semanas ${ }^{86}$. Apesar dos dados da literatura mostrarem que a incidência destes sintomas rebote ocorre em pequena porcentagem da população ${ }^{86,87}$, alguns estudos indicam que síndromes da retirada graves e incapacitantes podem ocorrem em até $5 \%$ dos pacientes ${ }^{88}$, requerendo uma modificação brusca na estratégia terapêutica desses indivíduos suscetíveis. A literatura revela que a paroxetina está associada com uma proporção significativamente maior de reações rebote (cerca de 5\% dos pacientes) em relação aos outros ISRS (fluoxetina, por exemplo), com deterioração em vários aspectos da saúde e do funcionamento orgânico ${ }^{86,89-92}$. A explicação para esta diferença relaciona-se à 'meia-vida longa' do principal metabólito da fluoxetina, que age como um tamponante natural ${ }^{93}$.

Como em outras classes de drogas, o efeito rebote não é específico para cada condição clínica (doença) particular em que o medicamento é utilizado, considerandose que a síndrome da descontinuação dos antidepressivos é semelhante (incidência, natureza e extensão) nos tratamentos da depressão, síndrome do pânico, ansiedade generalizada, ansiedade social e transtorno obsessivocompulsivo. De forma análoga, a duração do tratamento não influencia as reações de retirada ${ }^{94}$.

Em uma revisão dos mecanismos neurobiológicos que envolvem a síndrome da retirada dos antidepressivos, Harvey et al. ${ }^{95}$ sugeriram uma perspectiva molecular preliminar e uma hipótese sobre as implicações neuronais da descontinuação da medicação, descrevendo as evidências que suportam a associação do efeito rebote dos antidepressivos com os distúrbios na atividade cerebral do glutamato e nas sínteses do óxido nítrico e do ácido gama-aminobutírico. Da mesma forma que o tratamento antidepressivo crônico resulta na dessensibilização dos receptores de serotonina $\left(5-\mathrm{HT}_{1 \mathrm{~A}}\right)$ pré e pós-sinápticos, a interrupção abrupta da inibição da recaptação de 5-HT causa um déficit temporário na disponibilização de 5-HT intrasináptico em função da perda da inibição do controle póssináptico mediado pelos receptores $5-\mathrm{HT}_{1 \mathrm{~A}}$, promovendo um aumento paradoxal na circulação de 5-HT ${ }^{95-97}$.

Nos últimos anos, diversos estudos alertam para o aumento da 'suicidalidade' (ideações, tentativas ou comportamentos suicidas) em usuários de antidepressivos, evento adverso grave que pode ser explicado pelo efeito rebote, desde que a meia-vida ('time-point') das drogas seja valorizada na avaliação do fenômeno ${ }^{92,98,99}$. Meta-análise ${ }^{100}$ avaliou a relação entre antidepressivos e suicidalidade em 4.582 pacientes pediátricos, encontrando RR de 1,66 (IC $95 \% 1,02-2,68)$ nos ensaios randomizados com ISRSs para o tratamento da depressão e RR de 1,95 (IC 95\% 1,28-2,98) para todas as drogas e todas as doenças.

Outras meta-análises evidenciaram resultados semelhantes em adolescentes ${ }^{101}$ e adultos ${ }^{102,103}$, assim como estudo de caso-controle ${ }^{104}$ mostrou risco significativo de suicidalidade no início do tratamento e quando as doses foram descontinuadas (alteradas ou suspensas), alertando sobre os cuidados necessários no manejo dessa classe de drogas e fundamentando a ocorrência do efeito rebote e do princípio da similitude.

\section{EFEITO REBOTE DAS DROGAS HIPOLIPE- MIANTES (estatinas) ${ }^{11,13,16}$}

As estatinas são drogas amplamente prescritas para a redução do colesterol e são consideradas de primeira linha na prevenção da doença coronária e da aterosclerose. Atuam inibindo a enzima 3-hidroxi-3-metilglutaril-CoA (HMGCoA) redutase, limitante na biossíntese do colesterol endógeno e que catalisa a redução da HMG-CoA ao ácido mevalônico. A inibição desta enzima tem-se mostrado eficaz na redução do colesterol total, do colesterol de baixa densidade (LDL-C) e dos triglicerídeos, sendo útil no tratamento da aterosclerose e dos transtornos dislipidêmicos.

No entanto, os benefícios clínicos diretos das estatinas ultrapassam os seus efeitos hipolipemiantes. Além de reduzir a biossíntese do colesterol, a inibição do mevalonato pelas estatinas também reduz a síntese de importantes intermediários como os isoprenóides. Estes intermediários estão envolvidos na prenilação pós-traducional de diversas proteínas (Ras, Rho, Rac) que modulam uma variedade de processos, incluindo sinalização, diferenciação e proliferação celular. Dado o papel central destas proteínas isopreniladas na função endotelial, estabilidade da placa aterosclerótica, atividade plaquetária, coagulação, oxidação, respostas inflamatórias e imunológicas, podemse prever os efeitos primários benéficos destes compostos numa série de transtornos (doenças cardiovasculares, osteoporose, doença de Alzheimer e demência vascular relacionada, infecções, etc.). Esses 'efeitos pleiotrópicos' envolvem ações vasculoprotetoras com melhora da função endotelial, aumento na biodisponibilidade do óxido nítrico (ON) com efeitos antioxidantes, inibição de respostas inflamatórias e trombogênicas, ações imunomodulatórias, regulação de células progenitoras e estabilização de placas ateroscleróticas ${ }^{105-107}$.

Independente do aumento rebote na biossíntese do colesterol, evidências científicas sugerem que a interrupção súbita do tratamento com estatinas induz um agravamento rebote na atividade pleiotrópica (vasculoprotetora), 
aumentando a morbidade e a mortalidade de pacientes com doenças vasculares. A suspensão das estatinas induz uma elevada ativação das proteínas $G$ heterotriméricas (Rho e Rac), desencadeando a produção de espécies reativas de oxigênio e a supressão na biodisponibilidade do $\mathrm{ON}$, induzindo um estado pró-oxidante, pró-inflamatório e prótrombótico, com deterioração da função endotelial.

Estudos epidemiológicos indicaram que a interrupção da terapia em pacientes com IAM e AVC isquêmico (AVCI) confere, respectivamente, uma probabilidade significativamente maior de deterioração cardiológica e neurológica precoces, com desfechos graves. Em resumo, a suspensão do tratamento com estatinas resulta em rápido retorno à disfunção endotelial inicial e à amplificação dos processos oxidativos e inflamatórios, aumentando os riscos da ocorrência de eventos vasculares ${ }^{108-111}$.

Estudos experimentais descreveram os mecanismos fisiológicos e moleculares envolvidos na síndrome da retirada das estatinas, ampliando assim o conhecimento sobre o mecanismo de ação do efeito rebote: (i) aumento dos marcadores da biossíntese do colesterol ${ }^{112-116}$; (ii) deterioração da função endotelial ${ }^{113,117-119}$; (iii) aumento da inflamação e do estresse oxidativo ${ }^{120-123}$; e (iv) estimulação da resposta trombogênica ${ }^{113-116}$.

Estudos clínicos evidenciaram que a descontinuação das estatinas, especialmente após eventos vasculares agudos (IAM ou AVC), pode causar um efeito nocivo sobre os parâmetros cardiovasculares e a mortalidade (efeito rebote): pacientes que suspenderam o tratamento com estatinas apresentaram desfechos piores do que aqueles que mantiveram ou não utilizaram a droga. Estudos observacionais $^{124-129}$ descreveram que a suspensão das estatinas aumentou o risco de mortalidade (secundária a eventos vasculares fatais) em relação à manutenção $(2,3 \mathrm{a}$ 7,5 vezes) e à ausência (1,25 a 1,69 vezes) de tratamento. Estudos intervencionais mostraram que a suspensão das estatinas aumentou significativamente o risco de mortalidade em relação à manutenção do tratamento $(4,66$ vezes) $)^{130}$, além do risco de eventos vasculares fatais em relação à manutenção $(2,27$ a 8,67 vezes) e à ausência de tratamento $(19,01 \text { vezes) })^{130,131}$. A descontinuação das estatinas também é considerada preditora de mortalidade em um ano ${ }^{132}$.

Análise retrospectiva de 2.466 pacientes com hemorragia cerebral (2003-2008) ${ }^{133}$ descreveu a relação entre o uso e a descontinuação das estatinas na incidência do AVCI, avaliando a gravidade do evento e a mortalidade em 30 dias. Em geral, 537 (21,7\%) pacientes eram usuários de estatinas e foram menos propensos a apresentar AVCI severos na admissão hospitalar (54,7\% versus $63,3 \%)$, apesar de possuírem taxas semelhantes de desfechos desfavoráveis $(70 \%$ versus $67 \%)$ e mortalidade em 30 dias (36\% versus 37\%) em relação aos não usuários. As estatinas foram descontinuadas na admissão em 158 desses $537(29,4 \%)$ pacientes, que se mostraram mais propensos a apresentar AVCI grave $(65 \%$ versus $27 \%$; $\mathrm{P}<0,01)$, desfechos desfavoráveis $(90 \%$ versus $62 \% ; \mathrm{P}<0,01)$ e mortalidade em 30 dias (71\% versus $21 \%$; $\mathrm{P}<0,01)$. Após o ajuste para a gravidade do AVCI, a descontinuação das estatinas permaneceu associada a desfechos desfavoráveis (OR ajustado 2,4; IC 95\% 1,13-4,56) e elevada mortalidade (OR ajustado 2,0; IC 95\% 1,30-3,04). Os autores concluíram que a descontinuação das estatinas é um fator de piora nos desfechos e um marcador de mau prognóstico, conforme citado anteriormente.

Flint et al. ${ }^{134}$ apresentaram resultados semelhantes ao analisar os dados de 12.689 pacientes admitidos com AVCI em 17 hospitais americanos (2000-2007): pacientes que descontinuaram as estatinas na admissão apresentaram um risco de morte significativamente maior (RR 2,5; IC 95\% 2,1-2,9; $\mathrm{P}<0,001)$.

Ampliando o escopo de evidências sobre o princípio de cura homeopático, estudos recentes ${ }^{135-140}$ reforçaram as observações anteriores de que a suspensão das estatinas pode provocar deterioração rebote da função vascular (acidentes vasculares), alertando médicos e pacientes sobre esse evento adverso grave.

\section{EFEITO REBOTE DAS DROGAS SUPRESSORAS DA ACIDEZ GÁSTRICA ${ }^{12,13,16}$}

Segundo o FDA ${ }^{141}$, 'hipersecreção ácida rebote' é definida como "um aumento da secreção de ácido gástrico (basal e/ou estimulada) acima dos níveis pré-tratamento após a descontinuação da terapia antissecretora". Sendo inicialmente descrito com o uso dos antagonistas dos receptores $\mathrm{H}_{2}$ de histamina, esse rebote ácido está relacionado ao aumento da gastrina sérica e/ou ao aumento da regulação dos receptores $\mathrm{H}_{2}$. Níveis elevados de gastrina ou hipergastrinemia são efeitos secundários da inibição crônica da secreção de ácido gástrico, observada na terapia antissecretora de longo prazo. $\mathrm{O}$ aumento da gastrina plasmática estimula a produção e a liberação de histamina pelas células enterocromafins (ECL), que estimula as células parietais a produzirem ácido gástrico. Além disso, um aumento da massa de células parietais pode ocorrer juntamente com o uso crônico de agentes antissecretores, sendo esse um mecanismo adicional que explica o aumento da secreção ácida após a descontinuação do tratamento. Outra possível causa da secreção ácida rebote é o aumento da sensibilidade à histamina ${ }^{142}$.

A neutralização da acidez gástrica por antiácidos (hidróxido de alumínio/magnésio ou carbonato de cálcio), embora não seja um tratamento antissecretório, também pode causar acidez rebote após a suspensão do tratamento. Ensaios clínicos confirmaram essa hipótese ao observarem a ocorrência do efeito rebote após uma hora da administração de dose padrão de antiácidos a indivíduos sadios ${ }^{143,144}$.

De forma análoga a outras drogas antagonistas competitivas, os antagonistas do receptor $\mathrm{H}_{2}$ (cimetidina, 
famotidina, nizatidina e ranitidina) também causam hipersecreção ácida rebote após a retirada da droga. Embora o mecanismo exato ainda não esteja esclarecido, as principais hipóteses são de que o fenômeno rebote é causado pela maior capacidade de resposta dos receptores $\mathrm{H}_{2}$ à estimulação da histamina após inibição crônica competitiva, ou que o ramo inibidor da secreção ácida esteja comprometido ${ }^{145}$. Estudos com indivíduos saudáveis e pacientes mostraram que a hipersecreção ácida rebote após a descontinuação dos antagonistas dos receptores $\mathrm{H}_{2}$ ocorre dentro de 2-3 dias após 4 semanas de tratamento, permanecendo por 10 dias $^{146-149}$.

Inibidores da bomba de prótons (IBPs) (esomeprazol, lansoprazol, omeprazol e pantoprazol) bloqueiam o último passo da secreção ácida, promovendo intensa e persistente diminuição da acidez gástrica e concomitante aumento na liberação de gastrina. Esta hipergastrinemia rebote resulta em estimulação contínua das células ECL com consequente hiperhistaminemia, sem induzir o aumento da secreção ácida em vista do bloqueio da bomba de prótons. Além disso, a estimulação da proliferação de células ECL induz ao aumento da sua massa, que permanece por mais tempo do que o efeito dos IBPs quando a droga é descontinuada. Como em qualquer manifestação do fenômeno rebote, a hipersecreção ácida rebote torna-se evidente em determinado momento ('time-point') após a suspensão do tratamento, em função da meia-vida da droga. Após um período suficiente de tratamento com IBPs, a hipersecreção ácida rebote ocorre a partir da segunda semana (meia-vida dos IBPs) até a normalização da massa de células ECL (cerca de 2 meses), ou seja, 2-3 meses após a interrupção do tratamento. Esse fenômeno é prolongado, permanecendo por dois meses após igual curso de tratamento, com a persistência da hipersecreção ácida significativamente elevada $^{150-156}$.

A gastrina tem ação trófica sobre muitos tecidos, estimulando o crescimento in vitro de um grande número de linhagens de células tumorais, incluindo células de câncer de cólon. Embora alguns pesquisadores associem a hipergastrinemia ao risco aumentado de câncer de cólon, dois estudos populacionais de caso-controle realizados no Reino Unido (1987-2002) e na Dinamarca (1989-2005) não encontraram evidência de tal aumento em pacientes em uso regular de IBPs ${ }^{157-158}$. Porém, vale ressaltar que a hipergastrinemia rebote ocorre após algum tempo ('timepoint') da suspensão do tratamento, fato não valorizado nesses estudos.

O aumento da doença do refluxo gastroesofágico observado nas últimas décadas pode estar relacionado ao uso excessivo e indevido de IBPs. Analogamente, a hipergastrinemia pode ter um efeito sobre a progressão do esôfago de Barrett para o câncer de esôfago, em função de um evidente aumento na incidência do adenocarcinoma na junção cardioesofageana, que coincide com o aumento da terapia ácido-supressiva ${ }^{159-162}$. Estudo de coorte (1990-
$2003)^{163}$ mostrou relação direta entre o aumento na incidência de câncer gástrico e o aumento no uso de IBPs, comparativamente ao uso de antagonistas do receptor $\mathrm{H}_{2}$. Os autores sugerem que a hipergastrinemia é um fator de risco para o desenvolvimento de câncer gástrico, em consequência do uso excessivo de IBPs. Pelo mesmo motivo, observa-se aumento na incidência de tumores carcinóides gástricos (influência da hipergastrinemia na síndrome de Zollinger-Ellison e na gastrite atrófica) nas últimas três décadas $(400 \%$ em homens e $900 \%$ em mulheres) $)^{162,164-167}$.

Evidências clínicas da hipersecreção ácida rebote após a suspensão dos IBPs foram descritas em estudos de intervenção recentes ${ }^{168-172}$. Avaliando se a hipersecreção ácida rebote também ocorre em pacientes sem doença do refluxo gastroesofágico, alguns estudos descreveram piora dos sintomas em cerca de $70 \%$ dos usuários de longo prazo dos IBPs, após a descontinuação do tratamento ${ }^{168,170}$.

Outros estudos ${ }^{173-177}$ concluem pela existência da acidez rebote após a suspensão dos IBPs, convidando os profissionais da saúde a ponderarem sobre os riscos e benefícios dessa terapêutica, além de reiterarem a dinâmica do tratamento homeopático.

\section{EFEITO REBOTE DAS DROGAS INIBIDORAS DA REABSORÇÃO ÓSSEA ${ }^{13,14,16}$}

A osteoporose é uma doença caracterizada pela redução da massa óssea e o aumento da fragilidade esquelética, afetando 10 milhões de americanos e mais de 75 milhões de pessoas em todo o mundo (20-30\% de mulheres na pós-menopausa). Drogas antirreabsortivas como os bifosfonatos (BFs) são consideradas o tratamento de escolha para reduzir o risco de fraturas osteoporóticas: inibindo a reabsorção óssea pela diminuição da atividade dos osteoclastos, os BFs (alendronato, risedronato, ibandronato e ácido zoledrônico) promovem aumento na densidade mineral óssea (DMO), reduzindo o risco de fraturas. Nos EUA, entre 2005-2009, mais de 150 milhões de prescrições de BFs foram dispensadas a pacientes ambulatoriais $^{178}$.

Os BFs apresentam propriedades farmacológicas específicas que os diferem de outros inibidores da reabsorção óssea, como a retenção no esqueleto (matriz óssea) e a persistência dos efeitos por longo prazo após a suspensão do tratamento ${ }^{179}$. Essas características conferem uma 'meia-vida longa' aos BFs, dificultando a caracterização de um tempo específico para sua ação biológica ('time-point') e a consequente constatação temporal do efeito rebote.

Apesar do uso comprovado dos BFs para reduzir fraturas 'típicas' em pacientes com osteoporose, tem-se descrito nos últimos anos um aumento crescente de casos de fraturas 'atípicas' na região subtrocantérica ou na diáfise do fêmur com o uso dos BFs, com ausência de trauma ('low- 
energy trauma'). Em 2010, a American Society for Bone and Mineral Research (ASBMR) publicou o relatório de uma força-tarefa que estudou uma série de questões relacionadas a este transtorno ${ }^{180}$. Outras revisões sistemáticas discutiram as evidências clínicas e experimentais desse evento adverso secundário ao uso dos BFs, buscando compreender a patogênese do fenômeno ${ }^{181-185}$.

As fraturas atípicas de fêmur consequentes ao uso dos BFs apresentam características radiológicas específicas (orientação transversa ou oblíqua, ausência de cominuição, espessamento cortical, fratura por estresse ou reação de estresse no lado sintomático e/ou contralateral) e manifestações clínicas exclusivas (longo pródromo de dor, bilateralidade e lenta consolidação). $\mathrm{O}$ fato de essas fraturas atípicas ocorrerem na ausência de história pregressa de trauma sugere uma patogênese sistêmica, pois a grande maioria desse tipo de fratura está associada a traumas significativos (acidentes de automóveis, por exemplo), nos quais a energia transmitida ao osso resulta na propagação de várias linhas de fratura, produzindo cominuições. Apesar da baixa incidência, a morbidade dessa fratura é elevada.

Apesar da hipótese inicial para as fraturas atípicas sugerir que o longo tempo de ação dos BFs, suprimindo a remodelação óssea, poderia levar à 'hipermineralização' e ao 'acúmulo de microdanos' comprometendo a integridade óssea, análises histomorfométricas de biópsias de ossos afetados revelaram ausência de hipermineralização e de alterações nos cristais de hidroxiapatita, indicando aumento na maturidade mineral óssea sem qualquer modificação nos índices de cristalização (mineralização) após o tratamento ${ }^{184,186-189}$.

Analogamente às observações anteriores do efeito rebote em outras classes de drogas, estudos experimentais indicaram aumento paradoxal da atividade osteoclástica após a suspensão dos $\mathrm{BFs}^{185,186,190}$. Esse 'efeito antiosteolítico bifásico' foi demonstrado no aumento rebote dos marcadores da remodelação óssea (C-telopeptídeo tipo I do colágeno), das superfícies erodidas (3 vezes maior do que o basal) e do número de osteoclastos ativos (6 vezes maior do que o basal), após um decréscimo primário causado pela ação direta dos BFs. Essa magnitude do fenômeno rebote explica as fraturas completas sem trauma numa das regiões mais fortes do fêmur, assim como a demora na consolidação. Esses aspectos reforçam a hipótese do efeito rebote como principal mecanismo patogênico sistêmico das fraturas atípicas do fêmur. Outros estudos descreveram reabsorção óssea rebote após a suspensão de outras drogas antirreabsortivas (terapia hormonal e anticorpos monoclonais $)^{185}$.

Série de $\operatorname{casos}^{184}$ e estudos epidemiológicos ${ }^{191-195}$ evidenciaram claramente a associação entre o uso dos BFs por um período de tempo variável (3 meses a 9 anos) e a ocorrência dessas fraturas atípicas, descartando associação com o uso cumulativo da droga. Como citado anteriormente, esse período de tempo variável ('time- point') para a observação do fenômeno é consequência da meia-vida longa dos BFs (até 5 anos de ação após um ano de tratamento), peculiar aspecto das drogas de depósito que impede a observação do efeito rebote imediatamente após a suspensão do tratamento.

Enquanto a incidência de fratura de quadril diminuiu desde que os BFs começaram a ser usados nos EUA, fraturas subtrocantéricas ou na diáfise do fêmur aumentaram durante o mesmo período. Apesar destes tipos de fraturas representarem um subconjunto pequeno $(5-10 \%)$ de todas as fraturas de fêmur e quadril, fraturas subtrocantéricas exercem efeitos importantes na morbidade e na mortalidade, com resultados semelhantes aos observados nas fraturas de quadril ${ }^{196,197}$. Estudo prospectivo de 2 anos com 87 pacientes com fraturas subtrocantéricas mostrou taxa de mortalidade de $8 \%$ em 4 meses, $14 \%$ em 12 meses e $25 \%$ em 24 meses; cirurgia de revisão foi necessária em $8 \%$ e ao final do seguimento apenas $46 \%$ das pacientes recuperaram sua capacidade de andar, com $71 \%$ conseguindo viver em condições semelhantes àquelas de antes da fratura ${ }^{198}$.

Esses aspectos denotam o cuidado necessário com o manejo dos BFs, justificando os alertas crescentes a médicos e pacientes sobre a ocorrência desse evento adverso grave e endossando o tratamento através da similitude de sintomas.

\section{EFEITO REBOTE DAS DROGAS IMUNOMO- DULADORAS (natalizumabe) ${ }^{13,15,16}$}

Hipóteses atuais sustentam que o principal evento na patogênese da esclerose múltipla (EM) é a ativação dos linfócitos $\mathrm{T}$ auto-reativos na periferia que, após se proliferarem e atravessarem a barreira hemato-encefálica, desencadeiam uma cascata de eventos inflamatórios no SNC, culminando com a desmielinização e o dano axonal. A migração desses leucócitos através dessa barreira requer a interação com moléculas de adesão expressas na superfície das células, tais como selectinas, integrinas e seus receptores endoteliais. Natalizumabe é um anticorpo monoclonal humanizado, inibidor seletivo dessas moléculas de adesão, que impede a migração dos leucócitos ao SNC, reduzindo a frequência dos surtos, o número de lesões cerebrais e a progressão da doença.

Apesar dos efeitos primários benéficos do tratamento, estudos observacionais ${ }^{199-207}$ evidenciaram uma piora na atividade basal da doença após a suspensão do natalizumabe ('efeito rebote' ou 'síndrome inflamatória de reconstituição imune sem leucoencefalopatia multifocal progressiva' (208,209, com intensa exacerbação dos sintomas, aumento do número e/ou tamanho das lesões desmielinizantes e progressão da doença.

Assim como observado com natalizumabe ${ }^{210}$, fingolimode ${ }^{211}$ e drogas antagonistas do fator de necrose tumoral (infliximabe, adalimumabe, etanercepte) ${ }^{212}$, vale 
ressaltar que estudos recentes têm demonstrado uma alta frequência e intensidade de efeito rebote após a suspensão de outros agentes imunomoduladores usados em outras doenças, ${ }^{213-217}$ alertando para os riscos desta nova classe de drogas (modificadores da resposta biológica), que apresenta ação antagônica mais eficaz do que outras classes. Esta observação baseia-se em uma propriedade intrínseca ao fenômeno de rebote, na qual a magnitude da ação secundária do organismo é diretamente proporcional à intensidade da ação primária da droga.

\section{EMPREGO DOS FÁRMACOS MODERNOS SEGUNDO O PRINCÍPIO DA SIMILITUDE: USO TERAPÊUTICO DO EFEITO REBOTE218-224}

De forma análoga ao princípio da similitude terapêutica que a homeopatia emprega há mais de dois séculos, utilizando substâncias que causam determinados sintomas para tratar distúrbios semelhantes, recentemente, vem sendo sugerida pela farmacologia moderna uma nova estratégia de tratamento ('paradoxical pharmacology') 225${ }^{230}$, propondo que "a exacerbação de uma doença pode fazer com que os mecanismos compensatórios e redundantes do organismo consigam uma resposta benéfica em longo prazo", empregando os "efeitos paradoxais e bidirecionais das drogas" de forma terapêutica.

Essa 'farmacologia paradoxal' tem sido utilizada no emprego dos betabloqueadores e dos bloqueadores dos canais de cálcio na insuficiência cardíaca congestiva (ICC), melhorando a contratilidade ventricular e diminuindo a mortalidade $225,229,231,232$, além do emprego dos mesmos betabloqueadores no tratamento crônico da asma, promovendo broncodilatação e diminuição da inflamação nas vias respiratórias ${ }^{225,229,233}$. No uso do efeito paradoxal antidiurético das tiazidas para tratar o diabetes insipidus, reduzindo a poliúria e aumentando a osmolalidade da urina $^{234}$, e na aplicação do trióxido de arsênico $\left(\mathrm{As}_{2} \mathrm{O}_{3}\right)$, importante agente carcinogênico, como promissor agente antineoplásico (na leucemia promielocítica aguda) ${ }^{235,236}$. No emprego do efeito rebote dos contraceptivos orais como indutores da ovulação (gravidez) em mulheres portadoras de esterilidade funcional ${ }^{237}$, e na utilização de drogas estimulantes do sistema nervoso central (anfetamina, metilfenidato, pemolina, etc.) no tratamento da hiperatividade ${ }^{238,239}$, em vista de seu efeito bifásico. Dentre outros ${ }^{230}$.

De forma análoga ao método homeopático de tratamento, que utiliza 'doses infinitesimais' ou 'ultradiluições' dos medicamentos com o intuito de evitar uma possível agravação da doença na aplicação da similitude terapêutica, os proponentes desta proposta sugerem, como uma "boa regra geral", iniciar o tratamento com "doses muito pequenas, aumentando-as gradativamente ao longo das semanas" 225 .
Com o intuito de aproximar racionalidades distintas e ampliar o escopo da terapêutica pelos semelhantes, vimos propondo na última década uma sistematização para a utilização do efeito rebote curativo de 1.250 fármacos modernos, administrando-se aos indivíduos doentes, em doses infinitesimais ('medicamento dinamizado'), drogas que causaram eventos adversos semelhantes (segundo a 'totalidade de sintomas'), com o intuito de estimular uma reação paradoxal curativa do organismo ${ }^{218-224}$.

Para tornar esta proposta factível, foi elaborada uma Matéria Médica Homeopática dos Fármacos Modernos agrupando todos os efeitos primários ou patogenéticos (terapêuticos, adversos e colaterais) dos 1.250 fármacos modernos descritos em The United States Pharmacopeia Dispensing Information (USP DI) ${ }^{22}$, em conformidade com a distribuição dos capítulos da matéria médica homeopática tradicional. Para facilitar a 'seleção do medicamento individualizado’ - premissa indispensável ao sucesso do tratamento homeopático - a segunda etapa envolveu a elaboração de um Repertório Homeopático dos Fármacos Modernos, onde os sintomas patogenéticos e seus medicamentos correspondentes foram organizados numa disposição anátomo-funcional em conformidade com o repertório homeopático clássico.

Intitulado Novos Medicamentos Homeopáticos: uso dos fármacos modernos segundo o princípio da similitude $^{220-224}$, esse projeto de pesquisa está sistematizado e descrito em três livros eletrônicos (Fundamentação Científica do Princípio da Similitude na Farmacologia Moderna, Matéria Médica Homeopática dos Fármacos Modernos e Repertório Homeopático dos Fármacos Modernos) disponibilizados em um site bilíngue de livre acesso (http://www.newhomeopathicmedicines.com), permitindo que essa proposta seja analisada e aplicada por todos os colegas interessados.

\section{DISCUSSÃO}

A ação secundária ou reação vital do modelo homeopático está fundamentada no efeito rebote dos fármacos modernos, observado após a descontinuação de centenas de drogas empregadas em conformidade com o princípio terapêutico dos contrários (ação antagônica, antipática, paliativa ou enantiopática aos sintomas das doenças). Investigada pela fisiologia integrativa através do complexo sistema psico-neuro-imuno-endócrinometabólico, esta reação paradoxal ou homeostática ("life-preserving power", segundo Hahnemann) promove alterações orgânicas no sentido de manter o equilíbrio do meio interno alterado por fármacos, estímulos externos, aspectos psicoemocionais, etc.

Ampliando o espectro dessa reação paradoxal do organismo aos fatores psicoemocionais, estudos experimentais têm demonstrado que a inibição ou supressão dos pensamentos (pela terapia cognitiva, por exemplo) 
pode despertar um aumento paradoxal dos mesmos, que pode estar relacionado à etiopatogenia do agravamento de obsessões (transtornos obsessivo-compulsivos, etc.), fobias (fobia social, agorafobia, etc.), vícios (tabagismo, compulsão alimentar, etc.) e outras condições psicopatológicas $^{240-247}$.

A gravidade das manifestações paradoxais mencionadas, despertando eventos iatrogênicos fatais, está em conformidade com o conceito farmacológico de efeito rebote, no qual a reação secundária do organismo apresenta intensidade superior ao fenômeno semelhante inicialmente suprimido. Apesar do efeito rebote se manifestar em uma pequena proporção dos indivíduos, em vista de sua natureza idiossincrática, esses eventos paradoxais assumem importância epidemiológica quando se considera o enorme consumo de medicamentos paliativos pela população.

Nos estudos controlados anteriormente mencionados, o risco de eventos vasculares tromboembólicos foi 3,4 vezes maior após a suspensão do AAS, 1,52 vezes maior após a retirada de AINEs, 1,67 vezes maior após a retirada do rofecoxibe e 1,69 vezes maior após a retirada das estatinas. $\mathrm{O}$ risco de pensamentos e comportamentos suicidas foi 6 vezes maior após a retirada dos ISRSs, enquanto o risco de broncoespasmos paradoxais fatais foi 4 vezes maior após a suspensão dos LABAs. Em estudos observacionais, o agravamento da esclerose múltipla, com sérias complicações, ocorre em cerca de $10 \%$ dos pacientes que descontinuaram o tratamento com natalizumabe.

O tempo para a manifestação do efeito rebote após a descontinuação das drogas enantiopáticas de meia-vida curta não mostrou variação significativa: em média, 10 dias para o AAS, 14 dias para os AINEs, 9 dias para o rofecoxibe, 7 dias para os ISRSs, 7 dias para as estatinas e 7-14 dias para os IBPs. A duração do efeito rebote foi de até 30 dias com o rofecoxibe, 21 dias com os ISRSs e 30 dias com os IBPs. A duração do tratamento, antes da descontinuação da droga, não apresentou correlação com o risco de induzir eventos paradoxais.

Analogamente aos eventos paradoxais fatais de outras drogas paliativas modernas, as taxas de mortalidade por asma aumentaram desde que os beta-agonistas inalatórios foram introduzidos no mercado, sendo incrementadas substancialmente nas últimas décadas com o uso de broncodilatadores de ação primária mais potente (LABAs) $)^{248-252}$. LABAs causam, aproximadamente, 1 broncoespasmo rebote seguido de morte para cada 1.000 pacientes-ano-uso $^{77}$, correspondendo, em 2004, a 4.000-5.000 mortes apenas nos EUA (40.000-50.000 em todo o mundo $)^{9}$. ISRSs causam, aproximadamente, 5 manifestações suicidas rebotes para cada 1.000 adolescentes-ano-uso, correspondendo, em 2007, a 16.500 comportamentos ou pensamentos suicidas anuais apenas nos $\mathrm{EUA}^{10}$. Em vista do tromboembolismo rebote, AAS causa, aproximadamente, $4 \mathrm{IAM}^{28}$ e $5 \mathrm{AVC}^{29}$ para cada 1.000 pacientes-ano-uso ${ }^{27}$. Estudos descreveram o aumento da incidência de tumores carcinóides gástricos nas últimas décadas, em vista do consumo crescente dos IBPs ${ }^{12}$. BFs causam, aproximadamente, 1-3 fraturas atípicas paradoxais para cada 1.000 pacientes-ano-uso ${ }^{14}$. Em 2012, estima-se que em torno de 100.000 pacientes apresentaram agravação severa da EM após a suspensão do natalizumabe ${ }^{15}$.

Além das drogas citadas anteriormente, estudos recentes advertem para os evidentes riscos do efeito rebote das drogas analgésicas ${ }^{253-255}$ e psiquiátricas ${ }^{256-259}$, tendo em vista o elevado e crescente consumo pela população.

\section{CONCLUSÃO}

Um grande número de doenças iatrogênicas graves poderia ser evitado se a classe médica fosse elucidada sobre a ocorrência do efeito rebote dos fármacos modernos, minimizando o agravamento paradoxal do estado clínico com a descontinuação lenta e gradual ('desmame') dos medicamentos usados segundo o princípio dos contrários. Embora o efeito rebote não esteja incluído nos eventos adversos 'convencionais' das drogas, os “efeitos da descontinuação das drogas são parte da farmacologia das drogas" 18 e deveriam ser rotineiramente incorporados ao ensino da farmacologia moderna.

Em conformidade com os alertas de Hahnemann para "os tristes resultados do emprego de medicamentos antagonistas", renomados pesquisadores endossam o cuidado para com os riscos do efeito rebote dos fármacos modernos. Após observar os efeitos prejudiciais da descontinuação do AAS em pacientes coronarianos ${ }^{30}$, Emile Ferrari advertiu que a "terapia com aspirina não pode ser interrompida com segurança em caso algum, mas especialmente em pacientes com história de doença coronariana", enfatizando que essa evidência "serve como um lembrete para todos os médicos que tratam pacientes coronarianos de que a retirada da aspirina não deve ser aconselhada, devendo-se considerar recomendações alternativas" 260 .

Na mesma entrevista ${ }^{260}$, Richard Irwin, presidente na época do The American College of Chest Physicians, concluiu que "este estudo não só reforça a importância de que os pacientes coronarianos estejam em conformidade com a terapia com aspirina, mas envia uma mensagem para todos os médicos de que a decisão de descontinuar a terapia não deve ser tomada levianamente". De forma análoga, McColl e Gillen ${ }^{173}$ alertam para a evidência do fenômeno rebote com o uso dos IBPs, sinalizando que a prescrição liberal "é susceptível de criar a doença para a qual as drogas são projetadas para tratar, fazendo com que pacientes sem necessidade anterior de tal terapêutica passem a necessitar de tratamento intermitente ou em longo prazo".

Confirmando o princípio da similitude como 'lei natural e universal', as crescentes evidências sobre a ocorrência de eventos iatrogênicos graves e fatais após a suspensão de medicamentos paliativos demonstram a 
importância e a magnitude do fenômeno rebote (reação vital homeopática) em promover alterações profundas no equilíbrio orgânico. Aplicando este efeito rebote de forma curativa, a homeopatia estimula o organismo a reagir contra as suas próprias enfermidades.

Utilizando-se da observação pura, premissa da pesquisa qualitativa fenomenológica moderna, Hahnemann ultrapassou o pensamento científico de sua época, traçando diretrizes para o tratamento das doenças que são validadas atualmente pela ciência contemporânea, embora sejam desprezadas pela classe médica, desconhecedora de seus princípios.

\section{REFERÊNCIAS}

1. Teixeira MZ. Homeopatia: ciência, filosofia e arte de curar. Rev Med (São Paulo). 2006;85(2):30-43. Disponível em: http:// medicina.fm.usp.br/gdc/docs/revistadc_88_30-43\%20852.pdf.

2. Teixeira MZ. Evidências científicas da episteme homeopática. Rev Homeopatia (São Paulo). 2011;74(1-2):33-56. Disponível em: http://www.aph.org.br/revista/index.php/aph/article/ view/61/79.

3. Hahnemann S. Ensaio sobre um novo princípio para se averiguar o poder curativo das drogas. Rev Homeopatia (São Paulo). 1994;59(3-4):32-65.

4. Hahnemann S. Organon da arte de curar. 2a ed. Trad. Organon der Heilkunst. Ribeirão Preto: Museu de Homeopatia Abrahão Brickmann; 1995.

5. Teixeira MZ. Semelhante cura semelhante: o princípio de cura homeopático fundamentado pela racionalidade médica e científica. São Paulo: Editorial Petrus; 1998.

6. Teixeira MZ. Similitude in modern pharmacology. Homeopathy. 1999;88(3):112-20.

7. Teixeira MZ. Evidence of the principle of similitude in modern fatal iatrogenic events. Homeopathy. 2006;95(4):229-36. http:// dx.doi.org/10.1016/j.homp.2006.06.004.

8. Teixeira MZ. NSAIDs, Myocardial infarction, rebound effect and similitude. Homeopathy. 2007;96(1):67-8. http://dx.doi. org/10.1016/j.homp.2006.11.009.

9. Teixeira MZ. Bronchodilators, fatal asthma, rebound effect and similitude. Homeopathy. 2007;96(2):135-7. http://dx.doi. org/10.1016/j.homp.2007.02.001

10. Teixeira MZ. Antidepressants, suicidality and rebound effect: evidence of similitude? Homeopathy. 2009;98(1):114-21. doi: 10.1016/j.homp.2009.02.004.

11. Teixeira MZ. Statins withdrawal, vascular complications, rebound effect and similitude. Homeopathy. 2010;99(4):255-62. doi: 10.1016/j.homp.2010.01.001.

12. Teixeira MZ. Rebound acid hypersecretion after withdrawal of gastric acid suppressing drugs: new evidence of similitude. Homeopathy. 2011;100(3):148-56. doi: 10.1016/j. homp.2011.05.003.

13. Teixeira MZ. Rebound effect of drugs: fatal risk of conventional treatment and pharmacological basis of homeopathic treatment. Int J High Dilution Res. 2012;11(39):69-106.

14. Teixeira MZ. Antiresorptive drugs (bisphosphonates), atypical fractures and rebound effect: new evidence of similitude. Homeopathy. 2012;101(4):231-42. doi: 10.1016/j. homp.2012.07.001.

15. Teixeira MZ. Immunomodulatory drugs (natalizumab), worsening of multiple sclerosis, rebound effect and similitude. Homeopathy. 2013;102(3):215-24. doi: 10.1016/j.homp.2013.05.001.

16. Teixeira MZ. Efeito rebote dos fármacos modernos: evento

adverso grave desconhecido pelos profissionais da saúde. Rev Assoc Med Bras. 2013;59(6):629-38. http://dx.doi.org/10.1016/j. ramb.2013.05.003.

17. Webster's new world medical dictionary. 3rd ed. John Wiley Consumer; 2008.

18. Hodding GC, Jann M, Ackerman IP. Drug withdrawal syndromes - A literature review. West J Med. 1980;133:383-91. Available from: http://www.ncbi.nlm.nih.gov/pmc/articles/PMC1272349/ pdf/westjmed00231-0013.pdf.

19. Wolfe RM. Antidepressant withdrawal reactions. Am Fam Phys. 1997;56(2):455-62.

20. Oniani TN, Akhvlediani GR. Influence of some monoamine oxidase inhibitors on the sleep-wakefulness cycle of the cat. Neurosci Behav Physiol. 1988;18(4):301-6. Available from: http://download.springer.com/static/ $\mathrm{pdf} / 894 / \mathrm{art} \% 253 \mathrm{~A} 10.1007 \% 252 \mathrm{FBF} 01185522$. pdf?auth66=1392491191_e0263937bc0af97cc9d3ef149efb8d 19\&ext $=$.pdf.

21. Reidenberg MM. Drug discontinuation effects are part of the pharmacology of a drug. J Pharmacol Exp Ther. 2011;339(2):324-8. doi: 10.1124/jpet.111.183285.

22. The United States Pharmacopeial Convention. The United States Pharmacopeia Dispensing Information. Easton, Mack Printing Co.; 2004.

23. American Society of Hospital Pharmacists. American Hospital Formulary Service. Bethesda, Md.; 1990

24. Main C, Palmer S, Griffin S, Jones L, Orton V, Sculpher M, et al. Clopidogrel used in combination with aspirin compared with aspirin alone in the treatment of non-ST-segment-elevation acute coronary syndromes: a systematic review and economic evaluation. Health Technol Assess. 2004;8(40):1-156. DOI: $10.3310 / \mathrm{hta} 8400$

25. Lordkipanidzé M, Diodati JG, Pharand C. Possibility of a rebound phenomenon following antiplatelet therapy withdrawal: a look at the clinical and pharmacological evidence. Pharmacol Ther. 2009;123(2):178-86. doi: 10.1016/j.pharmthera.2009.03.019.

26. Maulaz AB, Bezerra DC, Michel P, Bogousslavsky J. Effect of discontinuing aspirin therapy on the risk of brain ischemic stroke. Arch Neurol. 2005;62:1217-20. doi:10.1001/ archneur.62.8.1217.

27. Rodríguez LA, Cea-Soriano L, Martín-Merino E, Johansson S. Discontinuation of low dose aspirin and risk of myocardial infarction: case-control study in UK primary care. BMJ. 2011;343:d4094. doi: http://dx.doi.org/10.1136/bmj.d4094.

28. García Rodríguez LA, Cea Soriano L, Hill C, Johansson S. Increased risk of stroke after discontinuation of acetylsalicylic acid: a UK primary care study. Neurology. 2011;76:740-6. doi: 10.1212/WNL.0b013e31820d62b5.

29. Sibon I, Orgogozo JM. Antiplatelet drug discontinuation is a 
risk factor for ischemic stroke. Neurology. 2004;62:1187-9. doi: 10.1212/01.WNL.0000118288.04483.02.

30. Ferrari E, Benhamou M, Cerboni P, Marcel B. Coronary syndromes following aspirin withdrawal: a special risk for late stent thrombosis. J Am Coll Cardiol. 2005;45(3):456-9. http:// dx.doi.org/10.1016/j.jacc.2004.11.041.

31. Biondi-Zoccai GG, Lotrionte M, Agostoni P, Abbate A, Fusaro $\mathrm{M}$, Burzotta F, et al. A systematic review and meta-analysis on the hazards of discontinuing or not adhering to aspirin among 50,279 patients at risk for coronary artery disease. Eur Heart J. 2006;27(22):2667-74. doi: 10.1093/eurheartj/ehl334.

32. Burger W, Chemnitius JM, Kneissl GD, Rücker G. Low-dose aspirin for secondary cardiovascular prevention - cardiovascular risks after its perioperative withdrawal versus bleeding risks with its continuation - review and meta-analysis. J Intern Med. 2005;257(5):399-414. doi: 10.1111/j.1365-2796.2005.01477.x

33. Václavík J, Táborský M. Antiplatelet therapy in the perioperative period. Eur J Intern Med. 2011;22(1):26-31. doi: 10.1016/j. ejim.2010.10.007.

34. Gerstein NS, Schulman PM, Gerstein WH, Petersen TR, Tawil I. Should more patients continue aspirin therapy perioperatively?: clinical impact of aspirin withdrawal syndrome. Ann Surg. 2012;255(5):811-9. doi: 10.1097/SLA.0b013e318250504e.

35. Collet JP, Montalescot G, Blanchet B, Tanguy ML, Golmard JL, Choussat R, et al. Impact of prior use or recent withdrawal of oral antiplatelet agents on acute coronary syndromes. Circulation. 2004;110(16):2361-7. doi: 10.1161/01.CIR.0000145171.89690. B4.

36. Lotrionte M, Biondi-Zoccai GG. The hazards of discontinuing acetylsalicylic acid therapy in those at risk of coronary artery disease. Curr Opin Cardiol. 2008;23(5):487-93. doi: 10.1097/ HCO.0b013e32830b5afa.

37. Ho PM, Peterson ED, Wang L, Magid DJ, Fihn SD, Larsen GC, et al. Incidence of death and acute myocardial infarction associated with stopping clopidogrel after acute coronary syndrome. JAMA. 2008;299(5):532-9. doi: 10.1001/jama.299.5.532.

38. Kim YD, Lee JH, Jung YH, Cha MJ, Choi HY, Nam CM, et al. Effect of warfarin withdrawal on thrombolytic treatment in patients with ischaemic stroke. Eur J Neurol. 2011;18(9):116570. doi: 10.1111/j.1468-1331.2011.03363.x.

39. Sambu N, Warner T, Curzen N. Clopidogrel withdrawal: is there a "rebound" phenomenon? Thromb Haemost. 2011;105(2):21120. doi: 10.1160/TH10-08-0554.

40. Andrioli G, Lussignoli S, Ortolani R, Minuz P, Vella F, Bellavite P. Dual effects of diclofenac on human platelet adhesion in vitro. Blood Coagul Fibrinolysis. 1996;7(2):153-6.

41. Andrioli G, Lussignoli S, Gaino S, Benoni G, Bellavite P. Study on paradoxical effects of NSAIDs on platelet activation. Inflammation. 1997;21(5):519-30.

42. Serebruany VL, Malinin AI, Bhatt DL. Paradoxical rebound platelet activation after painkillers cessation: missing risk for vascular events? Am J Med. 2006;119(8):707.e11-6. http:// dx.doi.org/10.1016/j.amjmed.2005.11.007.

43. Hernandez MR, Tonda R, Pino M, Serradell M, Arderiu G, Escolar G. Evaluation of effects of rofecoxib on platelet function in an in vitro model of thrombosis with circulating human blood. Eur J Clin Invest. 2004;34(4):297-302. DOI: 10.1111/j.13652362.2004.01334.x.

44. Fischer LM, Schlienger RG, Matter CM, Jick H, Meier CR.
Discontinuation of nonsteroidal anti-inflammatory drugs is associated with an increased risk of acute myocardial infarction. Arch Intern Med. 2004;164:2472-6. doi: 10.1001/ archinte.164.22.2472.

45. Barthélémy O, Limbourg T, Collet JP, Beygui F, Silvain J, Bellemain-Appaix A, et al. Impact of non-steroidal antiinflammatory drugs (NSAIDs) on cardiovascular outcomes in patients with stable atherothrombosis or multiple risk factors. Int J Cardiol. 2013;163(3):266-71. doi: 10.1016/j. ijcard.2011.06.015.

46. Griffin MR, Stein CM, Graham DJ, Daugherty JR, Arbogast PG, Ray WA. High frequency of use of rofecoxib at greater than recommended doses: cause for concern. Pharmacoepidemiol Drug Saf. 2004;13(6):339-43. doi: 10.1002/pds.879.

47. Ray WA, Stein CM, Daugherty JR, Hall K, Arbogast PG, Griffin MR. COX-2 selective non-steroidal anti-inflammatory drugs and risk of serious coronary heart disease. Lancet. 2002;360(9339):1071-3. http://dx.doi.org/10.1016/S01406736(02)11131-7

48. Johnsen SP, Larsson H, Tarone RE, McLaughlin JK, Norgard B, Friis S, et al. Risk of hospitalization for myocardial infarction among users of rofecoxib, celecoxib, and other NSAIDs: a population-based case-control study. Arch Intern Med. 2005;165(9):978-84. doi: 10.1001/archinte.165.9.978.

49. Levesque LE, Brophy JM, Zhang B. The risk for myocardial infarction with cyclooxygenase-2 inhibitors: a population study of elderly adults. Ann Intern Med. 2005;142(7):481-9. doi: 10.7326/0003-4819-142-7-200504050-00113.

50. Levesque LE, Brophy JM, Zhang B. Time variations in the risk of myocardial infarction among elderly users of COX-2 inhibitors. CMAJ. 2006;174(11):1563-9. doi:10.1503/cmaj.051679

51. Helin-Salmivaara A, Virtanen A, Vesalainen R, Grönroos JM, Klaukka T, Idänpään-Heikkilä JE, et al. NSAID use and the risk of hospitalization for first myocardial infarction in the general population: a nationwide case-control study from Finland. Eur Heart J. 2006;27(14):1657-63. doi: 10.1093/eurheartj/ehl053.

52. McGettingan P, Henry D. Cardiovascular risk and inhibition of cyclooxygenase: a systematic review of the observational studies of selective and nonselective inhibitors of cyclooxygenase 2 . JAMA. 2006;296(13):1633-44. doi: 10.1001/jama.296.13. jrv60011.

53. Kearney PM, Baigent C, Godwin J, Halls H, Emberson JR, Patrono C. Do selective cyclo-oxygenase-2 inhibitors and traditional non-steroidal anti-inflammatory drugs increase the risk of atherothrombosis? Meta-analysis of randomised trials. BMJ. 2006;332(7553):1302-8. doi: http://dx.doi.org/10.1136/ bmj.332.7553.1302

54. Fosbøl EL, Folke F, Jacobsen S, Rasmussen JN, Sørensen R, Schramm TK, et al. Cause-specific cardiovascular risk associated with nonsteroidal anti-inflammatory drugs among healthy individuals. Circ Cardiovasc Qual Outcomes. 2010;3(4):395405. doi: 10.1161/CIRCOUTCOMES.109.861104.

55. Amer M, Bead VR, Bathon J, Blumenthal RS, Edwards DN. Use of nonsteroidal anti-inflammatory drugs in patients with cardiovascular disease: a cautionary tale. Cardiol Rev. 2010;18(4):204-12. doi: 10.1097/CRD.0b013e3181ce1521.

56. Lordkipanidzé M, Harrison P. Beware of being caught on the rebound. J Thromb Haemost. 2011;9(1):21-3. doi: 10.1111/ j. 1538-7836.2010.04125.x.

57. Bavry AA, Khaliq A, Gong Y, Handberg EM, Cooper-Dehoff 
Teixeira MZ. Similia similibus curentur: o princípio de cura homeopático fundamentado na farmacologia moderna.

RM, Pepine CJ. Harmful effects of NSAIDs among patients with hypertension and coronary artery disease. Am J Med. 2011;124(7):614-20. doi: 10.1016/j.amjmed.2011.02.025

58. Vathenen AS, Knox AJ, Higgins BG, Britton JR, Tattersfield AE. Rebound increase in bronchial responsiveness after treatment with inhaled terbutaline. Lancet. 1988;1(8585):554-8. http:// dx.doi.org/10.1016/S0140-6736(88)91352-9.

59. Cochrane GM. Bronchial asthma and the role of beta 2 -agonists. Lung. 1990;168(Suppl):66-70.

60. Svedmyr N. The current place of beta 2-agonists in the management of asthma. Lung. 1990; 168 Suppl: 105-110.

61. Beach R, Young CL, Harkawat R, Gardiner PV, Avery AJ, Coward GA, et al. Effect on airway responsiveness of six weeks treatment with salmeterol. Pulm Pharmacol. 1993;6(2):155-7.

62. Yates DH, Sussman HS, Shaw MJ, Barnes PJ, Chung KF. Regular formoterol treatment in mild asthma. Effect on bronchial responsiveness during and after treatment. Am J Respir Crit Care Med. 1995;152(4 Pt 1):1170-4. doi: 10.1164/ ajrccm.152.4.7551366.

63. Bennett JA, Thompson Coon J, Pavord ID, Wilding PJ, Tattersfield AE. The airway effects of stopping regular oral theophylline in patients with asthma. Br J Clin Pharmacol. 1998;45(4):402-4. doi: 10.1046/j.1365-2125.1998.t01-1-00691.x.

64. Hancox RJ, Cowan JO, Flannery EM, Herbison GP, McLachlan CR, Taylor DR. Bronchodilator tolerance and rebound bronchoconstriction during regular inhaled beta-agonist treatment. Respir Med. 2000;94(8):767-71. http://dx.doi. org/10.1053/rmed.2000.0820.

65. van Schayck CP, Cloosterman SG, Bijl-Hofland ID, van den Hoogen H, Folgering HT, van Weel C. Is the increase in bronchial responsiveness or FEV1 shortly after cessation of beta2-agonists reflecting a real deterioration of the disease in allergic asthmatic patients? A comparison between short-acting and long-acting beta2-agonists. Respir Med. 2002;96(3):155-62.

66. Sears MR, Taylor DR, Print CG, Lake DC, Li QQ, Flannery EM, et al. Regular inhaled beta-agonist treatment in bronchial asthma. Lancet. 1990;336(8728):1391-6.

67. Lipworth BJ. Risks versus benefits of inhaled beta 2-agonists in the management of asthma. Drug Saf. 1992;7(1):54-70.

68. Wahedna I, Wong CS, Wisniewski AF, Pavord ID, Tattersfield AE. Asthma control during and after cessation of regular beta 2-agonist treatment. Am Rev Respir Dis. 1993;148(3):707-12.

69. Suissa S, Blais L, Ernst P. Patterns of increasing beta-agonist use and the risk of fatal or near-fatal asthma. Eur Respir J. 1994;7(9):1602-9. doi: 10.1183/09031936.94.07091602.

70. Salpeter SR, Ormiston TM, Salpeter EE. Meta-analysis: respiratory tolerance to regular beta2-agonist use in patients with asthma. Ann Intern Med. 2004;140(10):802-13. doi:10.7326/0003-4819-140-10-200405180-00018.

71. Johnson M. The beta-adrenoceptor. Am J Respir Crit Care Med. 1998;158(5 Pt 3):S146-53. doi: 10.1164/ajrccm.158. supplement_2.13tac110.

72. van Schayck CP, Bijl-Hofland ID, Cloosterman SG, Folgering HT, van der Elshout FJ, Van Weel C. Potential masking effect on dyspnoea perception by short- and long-acting beta2agonists in asthma. Eur Respir J. 2002; 19(2): 240-245. doi: 10.1183/09031936.02.00203602.

73. Hancox RJ. Concluding remarks: can we explain the association of beta-agonists with asthma mortality? A hypothesis. Clin Rev
Allergy Immunol. 2006;31(2-3):279-88. doi: http://dx.doi. org/10.1385/CRIAI:31:2:279

74. U.S. Food and Drug Administration. FDA Public Health Advisory: "Long-Acting Beta Agonist (LABA) Information". Available from: http://www.fda.gov/Drugs/DrugSafety/ InformationbyDrugClass/ucm199565.htm.

75. Lurie P, Wolfe SM. Misleading data analyses in salmeterol (SMART) study. Lancet. 2005;366(9493):1261-2; discussion 1262. http://dx.doi.org/10.1016/S0140-6736(05)67518-6.

76. Nelson HS, Weiss ST, Bleecker ER, Yancey SW, Dorinsky PM. The Salmeterol Multicenter Asthma Research Trial: a comparison of usual pharmacotherapy for asthma or usual pharmacotherapy plus salmeterol. Chest. 2006;129(1):15-26. doi: 10.1378/chest.129.1.15.

77. Salpeter SR, Buckley NS, Ormiston TM, Salpeter EE. Metaanalysis: effect of long-acting beta-agonists on severe asthma exacerbations and asthma-related deaths. Ann Intern Med. 2006;144(12):904-12. doi: 10.7326/0003-4819-144-12200606200-00126.

78. Guo JJ, Tsai K, Kelton CM, Bian B, Wigle PR. Risk of serious asthma exacerbations associated with long-acting beta agonists among patients with asthma: a retrospective cohort study. Ann Allergy Asthma Immunol. 2011;106(3):214-22. doi: 10.1016/j. anai.2010.12.008

79. Weatherall M, Wijesinghe M, Perrin K, Harwood M, Beasley R. Meta-analysis of the risk of mortality with salmeterol and the effect of concomitant inhaled corticosteroid therapy. Thorax. 2010;65(1):39-43. doi: 10.1136/thx.2009.116608

80. Cates CJ, Cates MJ. Regular treatment with formoterol for chronic asthma: serious adverse events. Cochrane Database Syst Rev. 2012;4:CD006923. doi: 10.1002/14651858.CD006923. pub3.

81. Williams D. Long-acting beta $\square$ agonists for asthma: a clinical paradox. Consult Pharm. 2010;25(11):756-9. doi: 10.4140/ TCP.n.2010.756.

82. Beasley R, Perrin K, Weatherall M, Wijesinghe M. Call for withdrawal of LABA single-therapy inhaler in asthma. Lancet. 2010;376(9743):750-1. doi: 10.1016/S0140-6736(10)61158-0.

83. Mysore S, Ruffin RE. Long-acting $\beta$-agonists in asthma management: what is the current status? Drugs. 2011;71(16):2091-7. doi: 10.2165/11596260-00000000000000 .

84. Lader M. Pharmacotherapy of mood disorders and treatment discontinuation. Drugs. 2007;67(12):1657-63. Available from: http://web.a.ebscohost.com/ehost/pdfviewer/ pdfviewer?sid=e42206a6-57d5-4992-b9a2-77d4ab711d41\%4 0sessionmgr4005\&vid $=2 \&$ hid $=4106$.

85. Schatzberg AF, Haddad P, Kaplan EM, Lejoyeux M, Rosenbaum JF, Young AH, et al. Serotonin reuptake inhibitor discontinuation syndrome: a hypothetical definition. J Clin Psychiatr. 1997;58(Suppl 7):5-10.

86. Tamam L, Ozpoyraz N. Selective serotonin reuptake inhibitor discontinuation syndrome: a review. Adv Ther. 2002;19(1):1726. Doi: 10.1007/BF02850015.

87. Price J, Waller P, Wood S, MacKay AV. A comparison of the post-marketing safety of four selective serotonin re-uptake inhibitors including the investigation of symptoms occurring on withdrawal. Br J Clin Pharmacol. 1996;42(6):757-63. doi: 10.1046/j.1365-2125.1996.00498.x. 
88. Haddad P, Anderson I, Rosenbaum JF. Antidepressant discontinuation syndromes. In: Haddad P, Dursun S, Deakin B, editors. Adverse syndromes and psychiatric drugs. Oxford: Oxford University Press; 2004. p.184-205.

89. Weller I. Report of the Committee on Safety of Medicines Expert Working Group on the safety of selective serotonin reuptake inhibitor antidepressants. London: London Stationery Office; 2005.

90. Rosenbaum JF, Fava M, Hoog SL, Ascroft RC, Krebs WB. Selective serotonin reuptake inhibitor discontinuation syndrome: a randomised clinical trial. Biol Psychiatr. 1998;44(2):77-87.

91. Hindmarch I, Kimber S, Cockle S. Abrupt and brief discontinuation of antidepressant treatment: effects on cognitive function and psychomotor performance. Int Clin Psychopharmacol. 2000;15(6):305-18.

92. Judge R, Parry M, Quail D, Jacobson JG. Discontinuation symptoms: comparison of brief interruption in fluoxetine and paroxetine treatment. Int Clin Psychopharmacol. 2002;17(5):21725 .

93. Zajecka J, Fawcett J, Amsterdam J, Quitkin F, Reimherr F, Rosenbaum J, et al. Safety of abrupt discontinuation of fluoxetine: a randomized, placebo-controlled study. J Clin Psychopharmacol. 1998;18(3):193-7.

94. Baldwin D, Montgomery SA, Nil R, Lader M. Discontinuation symptoms in depression and anxiety disorders. Int $\mathrm{J}$ Neuropsychopharmacol. 2007;10(1):73-84. doi: http://dx.doi. org/10.1017/S1461145705006358.

95. Harvey BH, RetiefR, KorffA, Wegener G. Increased hippocampal nitric oxide synthase activity and stress responsiveness after imipramine discontinuation: role of 5HT 2A/C-receptors. Metab Brain Dis. 2006; 21(2-3): 211-20. Doi; 10.1007/s11011006-9018-1.

96. Coupland NJ, Bell CJ, Potokar JP. Serotonin reuptake inhibitor withdrawal. J Clin Psychopharmacol. 1996;16(5):356-62.

97. Howland RH. Potential adverse effects of discontinuing psychotropic drugs: part 2: antidepressant drugs. J Psychosoc Nurs Ment Health Serv. 2010;48(7):9-12. doi: 10.3928/0279369520100527-98

98. Hiemke C, Härtter S. Pharmacokinetics of selective serotonin reuptake inhibitors. Pharmacol Ther. 2000;85(1):11-28. http:// dx.doi.org/10.1016/S0163-7258(99)00048-0

99. Tint A, Haddad PM, Anderson IM. The effect of rate of antidepressant tapering on the incidence of discontinuation symptoms: a randomised study. J Psychopharmacol. 2008;22(3):330-2. doi: 10.1177/0269881107087488.

100. Hammad TA, Laughren T, Racoosin J. Suicidality in pediatric patients treated with antidepressant drugs. Arch Gen Psychiatr. 2006; 63(3):332-9. doi: 10.1001/archpsyc.63.3.332.

101. Hetrick S, Merry S, McKenzie J, Sindahl P, Proctor M. Selective serotonin reuptake inhibitors (ISRSs) for depressive disorders in children and adolescents. Cochrane Database Syst Rev. 2007;(3):CD004851. doi: 10.1002/14651858.CD004851.pub2

102. Stone M, Laughren T, Jones ML, Levenson M, Holland PC, Hughes A, et al. Risk of suicidality in clinical trials of antidepressants in adults: analysis of proprietary data submitted to US Food and Drug Administration. BMJ. 2009;339:b2880. doi: 10.1136/bmj.b2880.

103. Carpenter DJ, Fong R, Kraus JE, Davies JT, Moore C, Thase ME. Meta-analysis of efficacy and treatment-emergent suicidality in adults by psychiatric indication and age subgroup following initiation of paroxetine therapy: a complete set of randomized placebo-controlled trials. J Clin Psychiatr. 2011;72(11):1503-14. doi: 10.4088/JCP.08m04927blu.

104. Valuck RJ, Orton HD, Libby AM. Antidepressant discontinuation and risk of suicide attempt: a retrospective, nested case-control study. J Clin Psychiatr. 2009;70(8):1069-77. doi: 10.4088/ JCP.08m04943.

105. Zhou Q, Liao JK. Statins and cardiovascular diseases: from cholesterol lowering to pleiotropy. Curr Pharm Des. 2009;15(5):467-78. doi: 10.2174/138161209787315684.

106. Ludman A, Venugopal V, Yellon DM, Hausenloy DJ. Statins and cardioprotection - more than just lipid lowering? Pharmacol Ther. 2009;122(1):30-43. doi: 10.1016/j.pharmthera.2009.01.002.

107. Bełtowski J, Wójcicka G, Jamroz-Wiśniewska A. Adverse effects of statins - mechanisms and consequences. Curr Drug Saf. 2009;4(3):209-28. doi: 10.2174/157488609789006949.

108. Endres M, Laufs U. Discontinuation of statin treatment in stroke patients. Stroke. 2006;37(10):2640-3. doi: 10.1161/01. STR.0000240690.69406.28.

109. Biccard BM. A peri-operative statin update for non-cardiac surgery. Part I: The effects of statin therapy on atherosclerotic disease and lessons learnt from statin therapy in medical (non-surgical) patients. Anaesthesia. 2008;63(1):52-64. doi: 10.1111/j.1365-2044.2007.05264.x

110. Williams TM, Harken AH. Statins for surgical patients. Ann Surg. 2008;247(1):30-7. doi: 10.1097/SLA.0b013e3181492c0d

111. Fuentes B, Martínez-Sánchez P, Díez-Tejedor E. Lipid-lowering drugs in ischemic stroke prevention and their influence on acute stroke outcome. Cerebrovasc Dis. 2009;27(Suppl 1):126-33. doi: 10.1159/000200450.

112. Stone BG, Evans CD, Prigge WF, Duane WC, Gebhard RL. Lovastatin treatment inhibits sterol synthesis and induces HMGCoA reductase activity in mononuclear leukocytes of normal subjects. J Lipid Res. 1989;30(12):1943-52. Available from: http://www.jlr.org/content/30/12/1943.long.

113. Puccetti L, Pasqui AL, Pastorelli M, Bova G, Di Renzo M, Leo A, et al. Platelet hyperactivity after statin treatment discontinuation. Thromb Haemost. 2003;90(3):476-82. http://dx.doi.org/10.1160/ TH03-02-0111.

114. Pappu AS, Bacon SP, Illingworth DR. Residual effects of lovastatin and simvastatin on urinary mevalonate excretions in patients with familial hypercholesterolemia. J Lab Clin Med. 2003;141(4):250-6. http://dx.doi.org/10.1067/mlc.2003.31.

115. Chen H, Ren JY, Xing Y, Zhang WL, Liu X, Wu P, et al. Shortterm withdrawal of simvastatin induces endothelial dysfunction in patients with coronary artery disease: a dose-response effect dependent on endothelial nitric oxide synthase. Int J Cardiol. 2009;131(3):313-20. doi:10.1016/j.ijcard.2007.10.044.

116. Chu CS, Lee KT, Lee MY, Su HM, Voon WC, Sheu SH, et al. Effects of atorvastatin and atorvastatin withdrawal on soluble CD40L and adipocytokines in patients with hypercholesterolaemia. Acta Cardiol. 2006;61(3):263-9. doi: 10.2143/AC.61.3.2014826

117. Laufs U, Endres M, Custodis F, Gertz K, Nickenig G, Liao JK, et al. Suppression of endothelial nitric oxide production after withdrawal of statin treatment is mediated by negative feedback regulation of rho GTPase gene transcription. Circulation. 2000;102(25):3104-10. doi: 10.1161/01.CIR.102.25.3104. 
Teixeira MZ. Similia similibus curentur: o princípio de cura homeopático fundamentado na farmacologia moderna.

118. Gertz K, Laufs U, Lindauer U, Nickenig G, Böhm M, Dirnagl $\mathrm{U}$, et al. Withdrawal of statin treatment abrogates stroke protection in mice. Stroke. 2003;34(2):551-7. doi: 10.1161/01. STR.0000054055.28435.BF.

119. Chen H, Ren JY, Xing Y, Zhang WL, Liu X, Wu P, et al. Shortterm withdrawal of simvastatin induces endothelial dysfunction in patients with coronary artery disease: a dose-response effect dependent on endothelial nitric oxide synthase. Int J Cardiol. 2009;131(3):313-20. doi: 10.1016/j.ijcard.2007.10.044.

120. Lee KT, Lai WT, Chu CS, Tsai LY, Yen HW, Voon WC, et al. Effect of withdrawal of statin on C-reactive protein. Cardiology. 2004;102(3):166-70. doi: 10.1159/000080486.

121. Li JJ, Li YS, Chu JM, Zhang CY, Wang Y, Huang Y, et al. Changes of plasma inflammatory markers after withdrawal of statin therapy in patients with hyperlipidemia. Clin Chim Acta. 2006;366(1-2):269-73. http://dx.doi.org/10.1016/j. cca.2005.10.021.

122. Thomas MK, Narang D, Lakshmy R, Gupta R, Naik N, Maulik $\mathrm{SK}$. Correlation between inflammation and oxidative stress in normocholesterolemic coronary artery disease patients 'on' and 'off' atorvastatin for short time intervals. Cardiovasc Drugs Ther. 2006;20(1):37-44. Doi: 10.1007/s10557-006-6752-x.

123. Sposito AC, Carvalho LS, Cintra RM, Araújo AL, Ono AH, Andrade JM, et al. Rebound inflammatory response during the acute phase of myocardial infarction after simvastatin withdrawal. Atherosclerosis. 2009;207(1):191-4. doi: 10.1016/j. atherosclerosis.2009.04.008.

124. Heeschen C, Hamm CW, Laufs U, Snapinn S, Böhm M, White HD. Withdrawal of statins in patients with acute coronary syndromes. Circulation. 2003;107(3):e27. doi: 10.1161/01. CIR.0000050552.32300.93.

125. Spencer FA, Fonarow GC, Frederick PD, Wright RS, Every $\mathrm{N}$, Goldberg RJ, et al. Early withdrawal of statin therapy in patients with non-ST-segment elevation myocardial infarction: national registry of myocardial infarction. Arch Intern Med. 2004;164(19):2162-8. doi:10.1001/archinte.164.19.2162.

126. Fonarow GC, Wright RS, Spencer FA, Fredrick PD, Dong W, Every N, et al. Effect of statin use within the first 24 hours of admission for acute myocardial infarction on early morbidity and mortality. Am J Cardiol. 2005;96(5):611-6. http://dx.doi. org/10.1016/j.amjcard.2005.04.029.

127. Schouten O, Hoeks SE, Welten GM, Davignon J, Kastelein JJ, Vidakovic R, et al. Effect of statin withdrawal on frequency of cardiac events after vascular surgery. Am J Cardiol. 2007;100(2):316-20. http://dx.doi.org/10.1016/j. amjcard.2007.02.093.

128. Cubeddu LX, Seamon MJ. Statin withdrawal: clinical implications and molecular mechanisms. Pharmacotherapy. 2006;26(9):1288-96. doi: 10.1592/phco.26.9.1288.

129. Risselada R, Straatman H, van Kooten F, Dippel DW, van der Lugt A, Niessen WJ, et al. Withdrawal of statins and risk of subarachnoid hemorrhage. Stroke. 2009;40(8):2887-92. doi: 10.1161/STROKEAHA.109.552760.

130. Blanco M, Nombela F, Castellanos M, RodriguezYáñez M, García-Gil M, Leira R, et al. Statin treatment withdrawal in ischemic stroke: a controlled randomized study. Neurology. 2007;69(9):904-910. doi: 10.1212/01. wnl.0000269789.09277.47

131. Lesaffre E, Kocmanová D, Lemos PA, Disco CM, Serruys PW. A retrospective analysis of the effect of noncompliance on time to first major adverse cardiac event in LIPS. Clin Ther. 2003;25(9):2431-47. http://dx.doi.org/10.1016/S01492918(03)80285-0

132. Colivicchi F, Bassi A, Santini M, Caltagirone C. Discontinuation of statin therapy and clinical outcome after ischemic stroke. Stroke. 2007; 38(10): 2652-2657. doi: 10.1161/ STROKEAHA.107.487017.

133. Dowlatshahi D, Demchuk AM, Fang J, Kapral MK, Sharma M, Smith EE; Registry of the Canadian Stroke Network. Association of statins and statin discontinuation with poor outcome and survival after intracerebral hemorrhage. Stroke. 2012; 43(6): 1518-1523. doi: 10.1161/STROKEAHA.111.645978

134. Flint AC, Kamel H, Navi BB, Rao VA, Faigeles BS, Conell $\mathrm{C}$, et al. Statin use during ischemic stroke hospitalization is strongly associated with improved poststroke survival. Stroke. 2012;43(1):147-54. doi: 10.1161/STROKEAHA.111.627729.

135. Pineda A, Cubeddu LX. Statin rebound or withdrawal syndrome: does it exist? Curr Atheroscler Rep. 2011;13(1):23-30. doi: 10.1007/s11883-010-0148-X.

136. Westover MB, Bianchi MT, Eckman MH, Greenberg SM. Statin use following intracerebral hemorrhage: a decision analysis. Arch Neurol. 2011;68(5):573-9. doi: 10.1001/archneurol.2010.356.

137. Flaster M, Morales-Vidal S, Schneck MJ, Biller J. Statins in hemorrhagic stroke. Expert Rev Neurother. 2011;11(8):1141-9. doi: 10.1586/ern.11.101.

138. Jasińska-Stroschein M, Owczarek J, Wejman I, OrszulakMichalak D. Novel mechanistic and clinical implications concerning the safety of statin discontinuation. Pharmacol Rep. 2011;63(4):867-79. Available from: http://www.if-pan.krakow. pl/pjp/pdf/2011/4_867.pdf.

139. Fallouh N, Chopra V. Statin withdrawal after major noncardiac surgery: risks, consequences, and preventative strategies. J Hosp Med. 2012;7(7):573-9. doi: 10.1002/jhm.1945.

140. Padala KP, Padala PR, McNeilly DP, Geske JA, Sullivan $\mathrm{DH}$, Potter JF. The effect of HMG-CoA reductase inhibitors on cognition in patients with Alzheimer's dementia: a prospective withdrawal and rechallenge pilot study. Am J Geriatr Pharmacother. 2012;10(5):296-302. doi: 10.1016/j. amjopharm.2012.08.002.

141. FDA 2000. Ome-Mg Briefing Document 20-0ct-00. Rebound of gastric acid secretion. Available from: http:/www.fda.gov/ ohrms/dockets/ac/00/backgrd/3650bla_11.pdf.

142. Waldum HL, Qvigstad G, Fossmark R, Kleveland PM, Sandvik AK. Rebound acid hypersecretion from a physiological, pathophysiological and clinical viewpoint. Scand J Gastroenterol. 2010;45(4):389-94. doi: 10.3109/00365520903477348.

143. Decktor DL, Robinson M, Maton PN, Lanza FL, Gottlieb S. Effects of aluminum/magnesium hydroxide and calcium carbonate on esophageal and gastric $\mathrm{pH}$ in subjects with heartburn. Am J Ther. 1995;2(8):546-52.

144. Monés J, Carrio I, Sainz S, Berná L, Clavé P, Liszkay M, et al. Gastric emptying of two radiolabelled antacids with simultaneous monitoring of gastric pH. Eur J Nucl Med. 1995;22(10):1123-8.

145. el-Omar E, Banerjee S, Wirz A, Penman I, Ardill JE, McColl KE. Marked rebound acid hypersecretion after treatment with ranitidine. Am J Gastroenterol. 1996;91(2):355-9. Available from: http://web.a.ebscohost.com/ehost/pdfviewer/ pdfviewer?sid=e151a88e-fce0-47b6-a023-d322ead2f713\%40s 
essionmgr4003\&vid $=2 \&$ hid $=4207$

146. Mohammed R, Holden RJ, Hearns JB, McKibben BM, Buchanan $\mathrm{KD}$, Crean GP. Effects of eight weeks' continuous treatment with oral ranitidine and cimetidine on gastric acid secretion, pepsin secretion, and fasting serum gastrin. Gut. 1983;24(1):61-6. Available from: http://www.ncbi.nlm.nih.gov/pmc/articles/ PMC1419923/pdf/gut00398-0077.pdf

147. Fullarton GM, McLauchlan G, Macdonald A, Crean GP, McColl KE. Rebound nocturnal hypersecretion after four weeks treatment with an $\mathrm{H} 2$ receptor antagonist. Gut. 1989;30(4):44954. Available from: http://gut.bmj.com/content/30/4/449.long

148. Fullarton GM, Macdonald AM, McColl KE. Rebound hypersecretion after $\mathrm{H} 2$-antagonist withdrawal - a comparative study with nizatidine, ranitidine and famotidine. Aliment Pharmacol Ther. 1991;5(4):391-8.

149. Smith AD, Gillen D, Cochran KM, El-Omar E, McColl KE. Dyspepsia on withdrawal of ranitidine in previously asymptomatic volunteers. Am J Gastroenterol. 1999;94(5):120913. doi: 10.1111/j.1572-0241.1999.01068.x

150. Solcia E, Rindi G, Silini E, Villani L. Enterochromaffin-like (ECL) cells and their growths: relationships to gastrin, reduced acid secretion and gastritis. Baillieres Clin Gastroenterol. 1993;7(1):149-65.

151. Håkanson R, Chen D, Tielemans Y, Andersson K, Ryberg B, Sundler F, et al. ECL cells: biology and pathobiology. Digestion. 1994;55(Suppl 3):38-45

152. Driman DK, Wright C, Tougas G, Riddell RH. Omeprazole produces parietal cell hypertrophy and hyperplasia in humans. Dig Dis Sci. 1996;41(10):2039-47. Doi: 10.1007/BF02093608

153. Waldum HL, Arnestad JS, Brenna E, Eide I, Syversen U, Sandvik AK. Marked increase in gastric acid secretory capacity after omeprazole treatment. Gut. 1996;39(5):649-53. Available from: http://gut.bmj.com/content/39/5/649.long

154. Gillen D, WirzAA, Ardill JE, McColl KE. Rebound hypersecretion after omeprazole and its relation to on-treatment acid suppression and Helicobacter pylori status. Gastroenterology. 1999; 116(2): 239-247.

155. Gillen D, Wirz AA, McColl KE. Helicobacter pylori eradication releases prolonged increased acid secretion following omeprazole treatment. Gastroenterology. 2004;126(4):980-8. http://dx.doi. org/10.1053/j.gastro.2004.01.004

156. Fossmark R, Johnsen G, Johanessen E, Waldum HL. Rebound acid hypersecretion after long-term inhibition of gastric acid secretion. Aliment Pharmacol Ther. 2005;21(2):149-54. DOI: 10.1111/j.1365-2036.2004.02271.x

157. Yang YX, Hennessy S, Propert K, Hwang WT, Sedarat A, Lewis JD. Chronic proton pump inhibitor therapy and the risk of colorectal cancer. Gastroenterology. 2007;133(3):748-54. http://dx.doi.org/10.1053/j.gastro.2007.06.022

158. Robertson DJ, Larsson H, Friis S, Pedersen L, Baron JA, Sørensen HT. Proton pump inhibitor use and risk of colorectal cancer: a population-based, case-control study. Gastroenterology. 2007;133(3):755-60. http://dx.doi. org/10.1053/j.gastro.2007.06.014

159. Hatlebakk JG, Hyggen A, Madsen PH, Walle PO, Schulz $\mathrm{T}$, Mowinckel $\mathrm{P}$, et al. Heartburn treatment in primary care: randomised, double blind study for 8 weeks. BMJ. 1999;319(7209):550-3. doi: http://dx.doi.org/10.1136/ bmj.319.7209.550
160. Loffeld RJ, van der Putten AB. Rising incidence of reflux oesophagitis in patients undergoing upper gastrointestinal endoscopy. Digestion. 2003;68(2-3):141-4. DOI:10.1159/000075308

161. Wang JS, Varro A, Lightdale CJ, Lertkowit N, Slack KN, Fingerhood ML, et al. Elevated serum gastrin is associated with a history of advanced neoplasia in Barrett's esophagus. Am J Gastroenterol. 2010;105(5):1039-45. doi: 10.1038/ ajg.2009.629.

162. McCarthy DM. Adverse effects of proton pump inhibitor drugs: clues and conclusions. Curr Opin Gastroenterol. 2010;26(6):62431. doi: 10.1097/MOG.0b013e32833ea9d9.

163. Poulsen AH, Christensen S, McLaughlin JK, Thomsen RW, Sørensen HT, Olsen JH, et al. Proton pump inhibitors and risk of gastric cancer: a population-based cohort study. Br J Cancer. 2009;100(9):1503-7. doi: 10.1038/sj.bjc.6605024.

164. Hung PD, Schubert ML, Mihas AA. Zollinger-Ellison Syndrome. Curr Treat Options Gastroenterol. 2003;6(2):163170.

165. Modlin IM, Lye KD, Kidd M. A 50-year analysis of 562 gastric carcinoids: small tumor or larger problem? Am J Gastroenterol. 2004;99(1):23-32. doi: 10.1046/j.1572-0241.2003.04027.x

166. Hodgson N, Koniaris LG, Livingstone AS, Franceschi D. Gastric carcinoids: a temporal increase with proton pump introduction. Surg Endosc. 2005;19(12):1610-12. Doi: 10.1007/s00464-0050232-4

167. Waldum HL, Gustafsson B, Fossmark R, Qvigstad G. Antiulce drugs and gastric cancer. Dig Dis Sci. 2005;50(Suppl 1):S39-44. Doi: 10.1007/s10620-005-2805-4

168. Björnsson E, Abrahamsson H, Simrén M, Mattsson N, Jensen C, Agerforz P, et al. Discontinuation of proton pump inhibitors in patients on long-term therapy: a double-blind, placebocontrolled trial. Aliment Pharmacol Ther. 2006;24(6):945-54. DOI: $10.1111 / \mathrm{j} .1365-2036.2006 .03084 . \mathrm{x}$

169. Reimer C, Søndergaard B, Hilsted L, Bytzer P. Proton-pump inhibitor therapy induces acid-related symptoms in healthy volunteers after withdrawal of therapy. Gastroenterology. 2009;137(1):80-7. doi: 10.1053/j.gastro.2009.03.058

170. Niklasson A, Lindström L, Simrén M, Lindberg G, Björnsson E. Dyspeptic symptom development after discontinuation of a proton pump inhibitor: a double-blind placebo-controlled trial. Am J Gastroenterol. 2010;105(7):1531-7. doi: 10.1038/ ajg.2010.81

171. Reimer C, Bytzer P. Discontinuation of long-term proton pump inhibitor therapy in primary care patients: a randomized placebo-controlled trial in patients with symptom relapse. Eur J Gastroenterol Hepatol. 2010;22(10):1182-8. doi: 10.1097/ MEG.0b013e32833d56d1.

172. Juul-Hansen P, Rydning A. Clinical and pathophysiological consequences of on-demand treatment with PPI in endoscopynegative reflux disease. Is rebound hypersecretion of acid a problem? Scand J Gastroenterol. 2011;46(4):398-405. doi: $10.3109 / 00365521.2010 .537684$

173. McColl KE, Gillen D. Evidence that proton-pump inhibitor therapy induces the symptoms it is used to treat. Gastroenterology. 2009;137(1):20-2. doi: 10.1053/j.gastro.2009.05.015

174. Ali T, Roberts DN, Tierney WM. Long-term safety concerns with proton pump inhibitors. Am J Med. 2009;122(10):896-903. doi: 10.1016/j.amjmed.2009.04.014.

175. Thomson AB, Sauve MD, Kassam N, Kamitakahara H. 
Teixeira MZ. Similia similibus curentur: o princípio de cura homeopático fundamentado na farmacologia moderna.

Safety of the long-term use of proton pump inhibitors. World J Gastroenterol. 2010;16(19):2323-30. doi: 10.3748/wjg.v16. i19.2323.

176. Oh S. Proton pump inhibitors - uncommon adverse effects. Aust Fam Physician. 2011;40(9):705-8. Available from: http://www.racgp.org.au/download/documents/AFP/2011/ September/201109oh.pdf

177. Niv Y. Gradual cessation of proton pump inhibitor (PPI) treatment may prevent rebound acid secretion, measured by the alkaline tide method, in dyspepsia and reflux patients. Med Hypotheses. 2011;77(3):451-2. doi: 10.1016/j.mehy.2011.06.007.

178. Whitaker M, Guo J, Kehoe T, Benson G. Bisphosphonates for Osteoporosis - Where Do We Go from Here? N Engl J Med. 2012;366(22):2048-51. doi: 10.1056/NEJMp1202619

179. Russell RGG, Watts NB, Ebetino FH, Rogers MJ. Mechanisms of action of bisphosphonates: similarities and differences and their potential influence on clinical efficacy. Osteoporos Int. 2008;19(6):733-59. doi: 10.1007/s00198-007-0540-8.

180. Shane E, Burr D, Ebeling PR, Abrahamsen B, Adler RA, Brown $\mathrm{TD}$, et al; American Society for Bone and Mineral Research. Atypical subtrochanteric and diaphyseal femoral fractures: report of a task force of the American Society for Bone and Mineral Research. J Bone Miner Res. 2010;25(11):2267-94. doi: $10.1002 / j b m r .1998$.

181. Schneider JP. Bisphosphonates and low-impact femoral fractures: current evidence on alendronate-fracture risk. Geriatrics. 2009;64(1):18-23. Available from: http://web.a.ebscohost.com/ ehost/pdfviewer/pdfviewer?sid=52916427-dbb2-4b8f-9a0b-308 ed1 ad83b6\%40sessionmgr4001\&vid $=2 \&$ hid $=4207$

182. Agarwal S, Agarwal S, Gupta P, Agarwal PK, Agarwal G, Bansal A. Risk of atypical femoral fracture with long-term use of alendronate (bisphosphonates): a systemic review of literature. Acta Orthop Belg. 2010;76(5):567-71. Available from: http://www.actaorthopaedica.be/acta/download/20105/01-Agarwal\%20et\%20al.pdf

183. Nieves JW, Cosman F. Atypical subtrochanteric and femoral shaft fractures and possible association with bisphosphonates. Curr Osteoporos Rep. 2010;8(1):34-9. doi: 10.1007/s11914010-0007-2.

184. Giusti A, Hamdy NA, Papapoulos SE. Atypical fractures of the femur and bisphosphonate therapy: a systematic review of case/ case series studies. Bone. 2010;47(2):169-80. doi: 10.1016/j. bone.2010.05.019.

185. Boonen S, Ferrari S, Miller PD, Eriksen EF, Sambrook PN, Compston J, et al. Postmenopausal osteoporosis treatment with antiresorptives: Effects of discontinuation or long-term continuation on bone turnover and fracture risk-a perspective. J Bone Miner Res. 2012;27(5):963-974. doi: 10.1002/ jbmr.1570.

186. Somford MP, Draijer FW, Thomassen BJ, Chavassieux PM, Boivin G, Papapoulos SE. Bilateral fractures of the femur diaphysis in a patient with rheumatoid arthritis on long-term treatment with alendronate: clues to the mechanism of increased bone fragility. J Bone Miner Res. 2009;24(10):1736-40. doi: 10.1359/jbmr.090408.

187. Zoehrer R, Roschger P, Paschalis EP, Hofstaetter JG, Durchschlag E, Fratzl P, et al. Effects of 3- and 5-year treatment with risedronate on bone mineralization density distribution in triple biopsies of the iliac crest in postmenopausal women. J Bone Miner Res. 2006;21(7):1106-12. DOI: 10.1359/jbmr.060401
188. Boivin G, Bala Y, Chapurlat RD, Delmas PD. Long-term treatment with oral bisphosphonates in postmenopausal women: effects on the degree of mineralization and microhardness of bone. J Bone Miner Res. 2008;23(Suppl 1):S10. Abstr. 1029. Available from: http://onlinelibrary.wiley.com/doi/10.1002/ jbmr.5650231302/full

189. Roschger P, Lombardi A, Misof BM, Maier G, Fratzl-Zelman $\mathrm{N}$, Fratzl P, et al. Mineralization density distribution of postmenopausal osteoporotic bone is restored to normal after long-term alendronate treatment: $\mathrm{qBEI}$ and sSAXS data from the Fracture Intervention Trial Long-Term Extension (FLEX). J Bone Miner Res. 2010;25(1):48-55. doi: 10.1359/jbmr.090702.

190. Kitano M, Ogata A, Sekiguchi M, Hamano T, Sano H. Biphasic anti-osteoclastic action of intravenous alendronate therapy in multiple myeloma bone disease. J Bone Miner Metab. 2005;23(1):48-52. Doi: 10.1007/s00774-004-0540-0

191. Abrahamsen B, Eiken P, Eastell R. Subtrochanteric and diaphyseal femur fractures in patients treated with alendronate: a register based national cohort study. J Bone Miner Res. 2009;24(6):1095-102. doi: 10.1359/jbmr.081247.

192. Black DM, Kelly MP, Genant HK, Palermo L, Eastell R, Bucci-Rechtweg C, et al; Fracture Intervention Trial Steering Committee; HORIZON Pivotal Fracture Trial Steering Committee. Bisphosphonates and fractures of the subtrochanteric or diaphyseal femur. N Engl J Med. 2010;362(19):1761-71. doi: 10.1056/NEJMoa1001086

193. Park-Wyllie LY, Mamdani MM, Juurlink DN, Hawker GA, Gunraj N, Austin PC, et al. Bisphosphonate use and the risk of subtrochanteric or femoral shaft fractures in older women. JAMA. 2011;305(8):783-9. doi: 10.1001/jama.2011.190.

194. Abrahamsen B, Eiken P, Eastell R. Cumulative alendronate dose and the long-term absolute aisk of subtrochanteric and diaphyseal femur fractures: a register-based national cohort analysis. J Clin Endocrinol Metab. 2010;95(12):5258-65. doi: 10.1210/jc.2010-1571.

195. Schilcher J, Michaelsson K, Aspenberg P. Bisphosphonate use and atypical fractures of the femoral shaft. N Engl J Med. 2011; 364(18): 1728-37. doi: 10.1056/NEJMoa1010650.

196. Nieves JW, Bilezikian JP, lane JM, Einhorn TA, Wang Y, Steinbuch M, et al. Fragility fractures of the hip and femur: incidence and patient characteristics. Osteoporos Int. 2010;21(3):399-408. doi: 10.1007/s00198-009-0962-6.

197. Wang Z, Bhattacharyya T. Trends in incidence of subtrochanteric fragility fractures and bisphosphonate use among the US elderly, 1996-2007. J Bone Miner Res. 2011;26(3):553-60. doi: 10.1002/ jbmr.233.

198. Ekstrom W, Nemeth G, Samnegard E, Dalen N, Tidermark J. Quality of life after a subtrochanteric fracture: a prospective cohort study on 87 elderly patients. Injury. 2009;40(4):371-6. doi: 10.1016/j.injury.2008.09.010.

199. Vellinga MM, Castelijns JA, Barkhof F, Barkhof F, Uitdehaag $\mathrm{BM}$, Polman $\mathrm{CH}$. Postwithdrawal rebound increase in T2 lesional activity in natalizumab-treated MS patients. Neurology. 2008;70(13 Pt 2):1150-1. doi: 10.1212/01. wnl.0000265393.03231.e5

200. Perumal J, Hreha S, Bao F, Zak I, Caon C, Tselis A, et al. Postnatalizumab associated rebound or CNS immune reconstitution syndrome: clinical and MRI findings. Mult Scler. 2009;15(Suppl 2):S119.

201. Killestein J, Vennegoor A, Strijbis EM, Strijbis EM, Seewann 
A, van Oosten BW, et al. Natalizumab drug holiday in multiple sclerosis: poorly tolerated. Ann Neurol. 2010; 68(3):392-5. doi: 10.1002/ana.22074.

202. Clifford DB, De Luca A, Simpson DM, Arendt G, Giovannoni G, Nath A. Natalizumab-associated progressive multifocal leukoencephalopathy in patients with multiple sclerosis: lessons from 28 cases. Lancet Neurol. 2010;9(4):438-46. doi: 10.1016/ S1474-4422(10)70028-4.

203. West TW, Cree BA. Natalizumab dosage suspension: are we helping or hurting? Ann Neurol. 2010;68(3):395-9. doi: 10.1002/ ana.22163.

204. Miravalle A, Jensen R, Kinkel RP. Immune reconstitution inflammatory syndrome in patients with multiple sclerosis following cessation of natalizumab therapy. Arch Neurol. 2011;68(2):186-91. doi: 10.1001/archneurol.2010.257

205. Kerbrat A, Le Page E, Leray E, Anani T, Coustans M, Desormeaux C, et al. Natalizumab and drug holiday in clinical practice: an observational study in very active relapsing remitting multiple sclerosis patients. J Neurol Sci. 2011;308(1-2):98-102. doi: 10.1016/j.jns.2011.05.043.

206. Borriello G, Prosperini L, Mancinelli C, Giannì C, Fubelli F, Pozzilli C. Pulse monthly steroids during an elective interruption of natalizumab: a post-marketing study. Eur J Neurol. 2012;19(5):783-7. doi: 10.1111/j.1468-1331.2011.03577.x.

207. Baumgartner A, Stich O, Rauer S. Clinical and radiological disease reactivation after cessation of long-term therapy with natalizumab. Int J Neurosci. 2012;122(1):35-9. doi: 10.3109/00207454.2011.622452.

208. Kleinschmidt-DeMasters BK, Miravalle A, Schowinsky J, Corboy J, Vollmer T. Update on PML and PML-IRIS occurring in multiple sclerosis patients treated with natalizumab. J Neuropathol Exp Neurol. 2012;71(7):604-17. doi: 10.1097/ NEN.0b013e31825caf2c.

209. Metz I, Radue EW, Oterino A, Kümpfel T, Wiendl H, Schippling $\mathrm{S}$, et al. Pathology of immune reconstitution inflammatory syndrome in multiple sclerosis with natalizumab-associated progressive multifocal leukoencephalopathy. Acta Neuropathol. 2012;123(2):235-45. doi: 10.1007/s00401-011-0900-5.

210. Laroni A, Bedognetti M, Uccelli A, Capello E, Mancardi GL. Association of melanoma and natalizumab therapy in the Italian MS population: a second case report. Neurol Sci. 2011;32(1):181-2. doi: 10.1007/s10072-010-0427-x.

211. Havla JB, Pellkofer HL, Meinl I, Gerdes LA, Hohlfeld R, Kümpfel T. Rebound of disease activity after withdrawal of fingolimod (FTY720) treatment. Arch Neurol. 2012;69(2):262-4. doi: 10.1001/archneurol.2011.1057.

212. Seror R, Richez C, Sordet C, Rist S, Gossec L, Direz G, et al. Pattern of demyelination occurring during anti-TNF- $\alpha$ therapy: a French national survey. Rheumatology (Oxford). 2013;52(5):868-74. doi: 10.1093/rheumatology/kes375.

213. Bone HG, Bolognese MA, Yuen CK, Kendler DL, Miller PD, Yang YC, et al. Effects of denosumab treatment and discontinuation on bone mineral density and bone turnover markers in postmenopausal women with low bone mass. J Clin Endocrinol Metab. 2011;96(4):972-80. doi: 10.1210/jc.20101502 .

214. Eisman JA, Bone HG, Hosking DJ, McClung MR, Reid IR, Rizzoli $\mathrm{R}$, et al. Odanacatib in the treatment of postmenopausal women with low bone mineral density: three-year continued therapy and resolution of effect. J Bone Miner Res. 2011;26(2):242-51. doi: 10.1002/jbmr.212.

215. Chen CI, Bergsagel PL, Paul H, Xu W, Lau A, Dave N, et al. Single-agent lenalidomide in the treatment of previously untreated chronic lymphocytic leukemia. J Clin Oncol. 2011;29(9):1175-81. doi: 10.1200/JCO.2010.29.8133.

216. Farsaci B, Higgins JP, Hodge JW. Consequence of dose scheduling of sunitinib on host immune response elements and vaccine combination therapy. Int J Cancer. 2012;130(8):1948-59. doi: 10.1002/ijc.26219.

217. Boyce A, Chong W, Yao J, Gafni RI, Kelly MH, Chamberlain CE, et al. Denosumab treatment for fibrous dysplasia. J Bone Miner Res. 2012;27(7):1462-70. doi: 10.1002/jbmr.1603.

218. Teixeira MZ. Homeopathic use of modern medicines: utilization of the curative rebound effect. Med Hypotheses. 2003;60(2):27683. http://dx.doi.org/10.1016/S0306-9877(02)00386-9

219. Teixeira MZ. 'Paradoxical strategy for treating chronic diseases': a therapeutic model used in homeopathy for more than two centuries. Homeopathy. 2005;94(4):265-6. http://dx.doi. org/10.1016/j.homp.2005.08.018

220. New homeopathic medicines: use of modern drugs according to the principle of similitude. São Paulo: Marcus Zulian Teixeira; 2010. 3v. available from: www.newhomeopathicmedicines. com.

221. Teixeira MZ. New homeopathic medicines: use of modern drugs according to the principle of similitude. Homeopathy. 2011;100(4):244-52. doi: 10.1016/j.homp.2011.01.002.

222. Teixeira MZ. Homeopathic use of modern drugs: therapeutic application of the paradoxical reaction of the organism or rebound effect. Int J High Dilution Res. 2011;10(37):338-52. Available from: http://www.feg.unesp.br/ ojs/index.php/ijhdr/ article/viewFile/456/542

223. Teixeira MZ. Novos medicamentos homeopáticos: uso dos fármacos modernos segundo o princípio de cura homeopático. Rev Homeopatia (São Paulo). 2012;75(1-2):36-53. Disponível em: http://www.aph.org.br/revista/index.php/aph/article/ viewFile $/ 240 / 313$

224. Teixeira MZ. 'New Homeopathic Medicines' database: a project to employ conventional drugs according to the homeopathic method of treatment. Eur J Integr Med. 2013;5(3):270-8. http:// dx.doi.org/10.1016/j.eujim.2013.01.001

225. Bond RA. Is paradoxical pharmacology a strategy worth pursuing? Trends Pharmacol Sci. 2001;22(6):273-6. http:// dx.doi.org/10.1016/S0165-6147(00)01711-9

226. Yun AJ, Lee PY, Bazar KA. Paradoxical strategy for treating chronic diseases where the therapeutic effect is derived from compensatory response rather than drug effect. Med Hypotheses. 2005;64(5):1050-9. http://dx.doi.org/10.1016/j. mehy.2004.09.007

227. Page C. Paradoxical pharmacology: turning our pharmacological models upside down. Trends Pharmacol Sci. 2011;32(4):197200. doi: 10.1016/j.tips.2011.02.006.

228. Davies CJ, Davies DM. Paradoxical reactions to commonly used drugs. Adverse Drug React Bull. 2011;211:807-10.

229. Bond RA, Giles H. For the love of paradox: from neurobiology to pharmacology. Behav Pharmacol. 2011;22(5-6):385-9. doi: 10.1097/FBP.0b013e328348ec6f.

230. Smith SW, Hauben M, Aronson JK. Paradoxical and bidirectional drug effects. Drug Saf. 2012;35(3):173-89. Doi: 10.2165/11597710-000000000-00000

231. Bristow MR. Beta-adrenergic receptor blockade in chronic 
Teixeira MZ. Similia similibus curentur: o princípio de cura homeopático fundamentado na farmacologia moderna.

heart failure. Circulation. 2000;101(5):558-69. doi: 10.1161/01. CIR.101.5.558

232. Ho CY. Hypertrophic cardiomyopathy in 2012. Circulation. 2012;125(11):1432-8. doi: $10.1161 /$ CIRCULATIONAHA.110.017277

233. Dickey BF, Walker JK, Hanania NA, Bond RA. BetaAdrenoceptor inverse agonists in asthma. Curr Opin Pharmacol. 2010;10(3):254-9. doi: 10.1016/j.coph.2010.03.002.

234. Loffing J. Paradoxical antidiuretic effect of thiazides in diabetes insipidus: another piece in the puzzle. Am Soc Nephrol. 2004;15(11):2948-50. DOI: 10.1097/01. ASN.0000146568.82353.04

235. Cui X, Kobayashi Y, Akashi M, Okayasu R. Metabolism and the paradoxical effects of arsenic: carcinogenesis and anticancer. Curr Med Chem. 2008;15(22):2293-304. doi: $10.2174 / 092986708785747526$

236. Platanias LC. Biological responses to arsenic compounds. J Biol Chem. 2009;284(28):18583-7. doi: 10.1074/jbc.R900003200

237. Kovács I. Examination of the rebound effect of biphasic oral contraceptives. Ther Hung. 1990;38(3):110-13.

238. Seeman P, Madras B. Methylphenidate elevates resting dopamine which lowers the impulse-triggered release of dopamine: a hypothesis. Behav Brain Res. 2002;130(1-2):79-83. http://dx.doi. org/10.1016/S0166-4328(01)00435-

239. Engert V, Pruessner JC. Dopaminergic and noradrenergic contributions to functionality in ADHD: the role of methylphenidate. Curr Neuropharmacol. 2008;6(4):322-8. doi: $10.2174 / 157015908787386069$

240. Rassin E, Merckelbach H, Muris P. Paradoxical and less paradoxical effects of thought suppression: a critical review. Clin Psychol Rev. 2000;20(8):973-95. http://dx.doi.org/10.1016/ S0272-7358(99)00019-7

241. Enticott PG, Gold RS. Contrasting the ironic monitoring and motivational explanations of postsuppressional rebound. Psychol Rep. 2002;90(2):447-50.

242. Fehm L, Margraf J. Thought suppression: specificity in agoraphobia versus broad impairment in social phobia? Behav Res Ther. 2002;40(1):57-66.

243. Erskine JA, Georgiou GJ, Kvavilashvili L. I suppress, therefore I smoke: effects of thought suppression on smoking behavior. Psychol Sci. 2010;21(9):1225-30. doi: 10.1177/0956797610378687.

244. Erskine JA, Georgiou GJ. Effects of thought suppression on eating behavior in restrained and non-restrained eaters. Appetite. 2010;54(3):499-503. doi: 10.1016/j.appet.2010.02.001

245. Denzler M, Förster J, Liberman N, Rozenman M. Aggressive, funny, and thirsty: a Motivational Inference Model (MIMO) approach to behavioral rebound. Pers Soc Psychol Bull. 2010;36(10):1385-96. doi: 10.1177/0146167210382663.

246. Geeraert N, Van Boven L, Yzerbyt VY. Similarity on the rebound: inhibition of similarity assessment leads to an ironic postsuppressional rebound. Q J Exp Psychol (Colchester). 2011;64(9):1788-96. doi: 10.1080/17470218.2011.557737.

247. Bryant RA, Wyzenbeek M, Weinstein J. Dream rebound of suppressed emotional thoughts: the influence of cognitive load. Conscious Cogn. 2011;20(3):515-22. doi: 10.1016/j. concog.2010.11.004

248. Stolley PD. Asthma mortality. Why the United States was spared an epidemic of deaths due to asthma. Am Rev Respir Dis. 1972;105(6):883-90.

249. Keating G, Mitchell EA, Jackson R, Beaglehole R, Rea H. Trends in sales of drugs for asthma in New Zealand, Australia, and the United Kingdom, 1975-81. Br Med J (Clin Res Ed). 1984;289(6441):348-51. Available from: http://www.ncbi.nlm. nih.gov/pmc/articles/PMC1442331/pdf/bmjcred00514-0016. pdf

250. Mormile F, Chiappini F, Feola G, Ciappi G. Deaths from asthma in Italy (1974-1988): is there a relationship with changing pharmacological approaches? J Clin Epidemiol. 1996;49(12):1459-66. http://dx.doi.org/10.1016/S08954356(96)00188-6

251. Pearce N, Beasley R, Crane J, Burgess C, Jackson R. End of the New Zealand asthma mortality epidemic. Lancet. 1995;345(8941):41-4. http://dx.doi.org/10.1016/S01406736(95)91159-6

252. Beasley R, Pearce N, Crane J, Burgess C. Beta-agonists: what is the evidence that their use increases the risk of asthma morbidity and mortality? J Allergy Clin Immunol. 1999;104(2 Pt 2):S18-30

253. Garza I, Schwedt TJ. Diagnosis and management of chronic daily headache. Semin Neurol. 2010;30(2):154-66. doi: 10.1055/s0030-1249224.

254. Couch JR. Update on chronic daily headache. Curr Treat Options Neurol. 2011;13(1):41-55. doi: 10.1007/s11940-010-0104-7.

255. Cevoli S, Cortelli P. Italian Law "measures to guarantee the access to palliative and pain treatments": rebound on headaches' management. Neurol Sci. 2011;32( Suppl 1):S77-9. doi: 10.1007/ s10072-011-0550-3.

256. Correll CU. From receptor pharmacology to improved outcomes: individualising the selection, dosing, and switching of antipsychotics. Eur Psychiatry. 2010; 25 Suppl 2: S12-21. doi: 10.1016/S0924-9338(10)71701-6.

257. Howland RH. Potential adverse effects of discontinuing psychotropic drugs. Part 1: Adrenergic, cholinergic, and histamine drugs. J Psychosoc Nurs Ment Health Serv. 2010;48(6):11-4. doi: 10.3928/02793695-20100506-01.

258. Howland RH. Potential adverse effects of discontinuing psychotropic drugs: part 2: antidepressant drugs. J Psychosoc Nurs Ment Health Serv. 2010;48(7):9-12. doi: 10.3928/0279369520100527-98

259. Howland RH. Potential adverse effects of discontinuing psychotropic drugs. Part 3: Antipsychotic, dopaminergic, and mood-stabilizing drugs. J Psychosoc Nurs Ment Health Serv. 2010;48(8):11-4. doi: 10.3928/02793695-20100708-01.

260. Aetna InteliHealth, Harvard Medical School. Health News: Aspirin withdrawal may pose risk to coronary patients. Available from: http://www.intelihealth.com/IH/ihtIH/ WSAZR000/333/341/371250.html. 